\title{
EXPECTED INTERNATIONAL DEMAND FOR WOODY AND HERBACEOUS FEEDSTOCK
}

Patrick Lamers, Jacob Jacobson, Roni Mohammad, Christopher Wright

December 2014

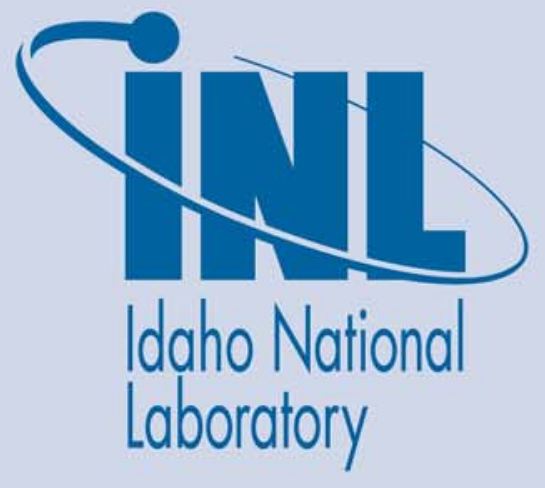

The INL is a U.S. Department of Energy National Laboratory operated by Battelle Energy Alliance 
INL/EXT-14-33968

\title{
EXPECTED INTERNATIONAL DEMAND FOR WOODY AND HERBACEOUS FEEDSTOCK
}

Patrick Lamers, Jacob Jacobson, Roni Mohammad, Christopher Wright

December 2014

\author{
Idaho National Laboratory \\ Idaho Falls, Idaho 83415
}

http://www.inl.gov

Prepared for the

U.S. Department of Energy

Office of Energy Efficiency and Renewable Energy

Under DOE Idaho Operations Office

Contract DE-AC07-05ID14517 


\begin{tabular}{|c|c|}
\hline $\begin{array}{l}\text { D\#: 1.2.1.5.DL.1 } \\
\text { Type: Milestone } \\
\text { WBS \#: } 1.2 .1 .5\end{array}$ & $\begin{array}{l}\text { Completion Date: 12/23/2014 } \\
\text { Scheduled Completion: 12/31/2014 } \\
\text { Platform Area: Feedstocks }\end{array}$ \\
\hline Milestone Title: & Expected international demand for woody and herbaceous feedstock \\
\hline Authors: & $\begin{array}{l}\text { Patrick Lamers, Jacob Jacobson, Roni Mohammad, Christopher } \\
\text { Wright }\end{array}$ \\
\hline $\begin{array}{l}\text { Project Name: } \\
\text { Project Leader: }\end{array}$ & $\begin{array}{l}\text { International Feedstocks } \\
\text { J. Richard Hess }\end{array}$ \\
\hline Key Words: & International biomass trade, Feedstock logistics \\
\hline
\end{tabular}

INL/EXT-14-33968

This report contains business sensitive and/or potential intellectual property information. Written permission from the author must be obtained prior to distribution beyond Laboratory and DOE staff.

\section{Milestone Objective}

Deliver international demand curves for generic woody and herbaceous feedstocks (no more than four) that meet end user quality specifications. A technical memo delivered to BETO will document the projected 2022, 2030, 2040 international demand curves by region and quality requirements for commodity feedstock pellets that could potentially be sourced from U.S. biomass supplies. The data behind the demand curves will identify potential international competitors/markets for U.S. biomass supplies that form the basis for the 2022, 2030, and 2040 renewable fuels volume targets from feedstocks such as pulpwood, logging residues, corn stover, and switchgrass. 


\section{Executive Summary}

The development of a U.S. bioenergy market and ultimately 'bioeconomy' has primarily been investigated with a national focus. Limited attention has been given to the potential impacts of international market developments. The goal of this project is to advance the current State of Technology of a single biorefinery to the global level providing quantitative estimates on how international markets may influence the domestic feedstock supply costs. The scope of the project is limited to feedstock that is currently available and new crops being developed to be used in a future U.S. bioeconomy including herbaceous residues (e.g., corn stover), woody biomass (e.g., pulpwood), and energy crops (e.g., switchgrass). The timeframe is set to the periods of 2022, 2030, and 2040 to align with current policy targets (e.g., the RFS2) and future updates of the Billion Ton data.

This particular milestone delivers demand volumes for generic woody and herbaceous feedstocks for the main (net) importing regions along the above timeframes. The regional focus of the study is the European Union (EU), currently the largest demand region for U.S. pellets made from pulpwood and forest residues. The pellets are predominantly used in large-scale power plants $\left(>5 \mathrm{MW}_{\mathrm{el}}\right)$ in the United Kingdom (UK), the Netherlands (NL), Belgium (BE), and Denmark (DK).

The report reviews state-of-technology modeling efforts to conclude upon primary biomass demand and trade trends on global level via general/partial equilibrium models (taking a topdown approach across energy resources and markets), and regional level via bottom-up models (covering industry status, production capacity, etc. in shorter timeframes). To project global bioenergy demand trends, the latest policy projections of the World Energy Outlook (WEO) (IEA 2014) were applied. EU demand and biomass supply projections were based on the GREEN-X model, which has been successfully applied in several multi-year European Commission research projects to analyze EU renewable energy targets and related policy schemes.

The comparisons show that the output of modern biomass for energy expands across all sectors, while the use of traditional biomass is projected to decline until 2040. The majority of new biomass conversion facilities are projected to occur in the power generation sector. The largest absolute primary biomass demand increases until 2040 are expected to occur in the U.S. (+4.58 EJ), the EU (+3.72 EJ), and China (+2.34 EJ), followed by Brazil (+2.27 EJ) and India $(+1.89 \mathrm{EJ})$. Russia is expected to triple, Japan to almost double its primary biomass demand from 2012 to 2040; albeit their total national demand will still be less than 1 EJ by 2040 .

Feedstock demand portfolios per country were derived from sector demand assumptions with respect to technological suitability, past, and expected future industry trends. The results indicate that the EU and Japanese demand are dominated by woody biomass while herbaceous residues play a much larger role in Brazil, India, China, and the U.S. (Figure 1). 
$=$

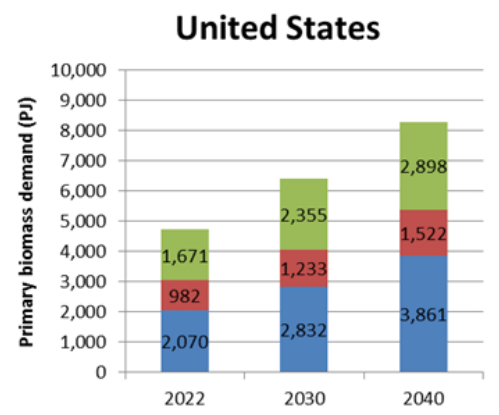

Japan

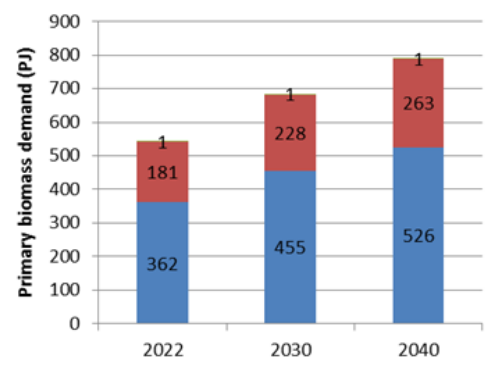

China

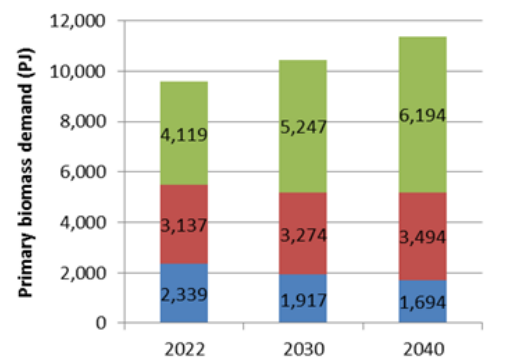

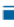
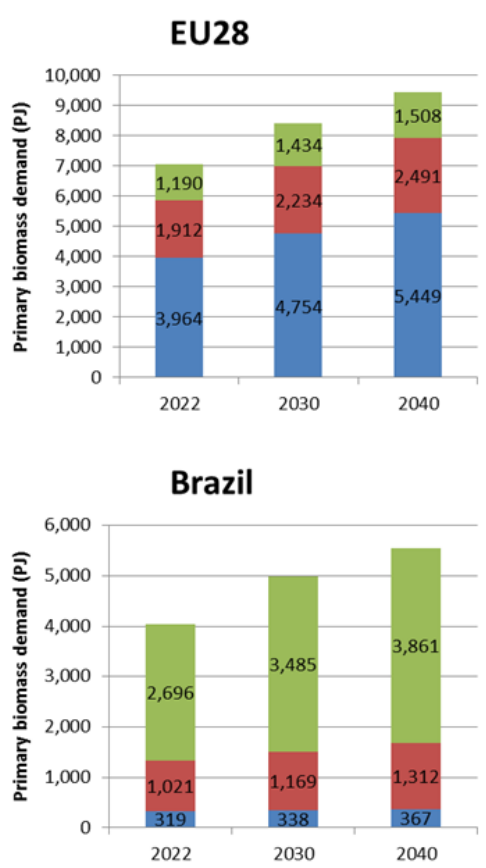

I- Herbaceous residues

- Forest residues

- Pulpwood

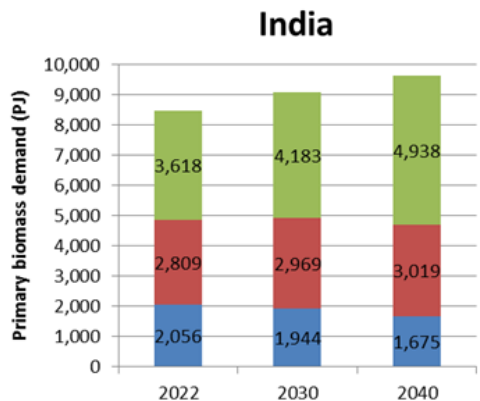

Figure 1. Feedstock demand estimates for selected countries/regions.

The region's/country's trade portfolio is directly related to their expected local biomass mobilization levels (in volume and costs). Top-down models indicate that by 2040 the main exporting regions will include Russia, Latin America, Oceania, and Africa. A cross-check with current trade flows and main trading regions however suggests that in the mid-term, the main exporting regions will be limited to current main exporting regions. These include the U.S. and Canada for solid biomass and Brazil for liquid biofuels. Russia has so far not been able to mobilize significant volumes of woody biomass for export on a large-/country-scale, although some individual, larger projects exist. Despite their large technical biomass potential, Latin America, Africa, and Oceania do not export any significant volumes of solid biomass at the moment, and it is highly unlikely that sufficient investments in infrastructure will be realized in order to mobilize large volumes by 2030 from these regions in the medium-term.

Current U.S. exports of woody biomass are expected to increase further - at least until 2022, most likely however until 2030 and potentially also to 2040. The primary reason is that the main destination of U.S. woody biomass exports, the EU, is expected to remain a net importer of 
woody biomass until 2040. This is a consensus across all studies reviewed. The current policy incentive schemes in the EU will remain in place at least through 2027 (e.g., in the UK). Following, U.S. exports could find new markets in Asia or locally. The eventual direction of the biomass flows will largely be determined by U.S. policy and industry developments in the advanced biofuels sector and the use of biomass for electricity. Also, other market developments to supply biomass for export, in particular from Brazil may shift interest from oversea buyers away from U.S. sources. Given current U.S. wood pellet production capacity increases, which are partly driven by EU power companies as upstream investments, and less stable investment climates in other potential export regions (e.g., Latin America), and their limited logistics network (for export), suggest that this scenario however is rather unlikely.

The current and expected future main EU importing countries of U.S. wood pellets include the United Kingdom (UK), the Netherlands (NL), Belgium (BE), and Denmark (DK). Herbaceous biomass demand in these countries is import dependent as the combined countries' domestic supply exceeds the projected demand. Unless herbaceous biomass can fully substitute woody biomass in the heat and electricity markets, corn stover and switchgrass based exports are therefore less relevant for the U.S. in the mid-term (until 2030).

U.S. wood pellet exports (based on either pulpwood or forest residues) will remain competitive against EU domestic supply, as long as they remain under the domestic supply curve.

Assuming that residential fuelwood heating demand would be satisfied domestically, and that all forest residues (low cost woody biomass supply fraction) would be used prior to imports, the additional demand for woody feedstock in the form of pellets for the UK, NL, BE, and DK combined reaches 228 PJ (14 Mtons) in 2022, 304 PJ (19 Mtons) in 2030, and 339 PJ (21 Mtons) in 2040. Imports of this volume would compete with domestic pulpwood pellets up to supply costs (including cost, insurance, and freight/transport to large harbors in the EU) of:

- 2022: US\$150 per ton,

- 2030: US\$160 perton,

- 2040: US\$175 per ton.

Or forest residue based pellets up to supply costs of:

- 2022: US\$85 per ton,

- 2030: US\$89 per ton,

- 2040: US\$98 per ton. 


\section{Table of Contents}

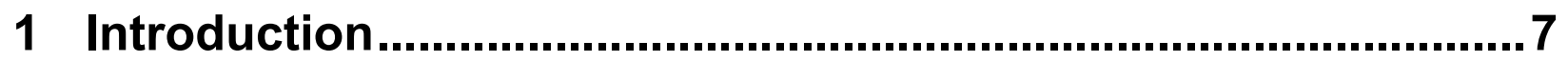

1.1 Project background and milestone context............................................... 7

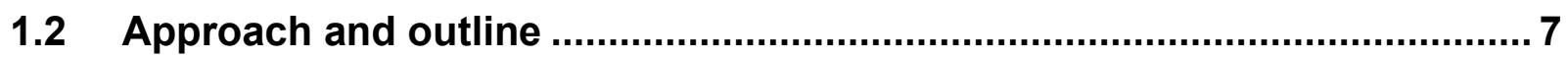

2 Global biomass demand trends until 2040 ............................. 9

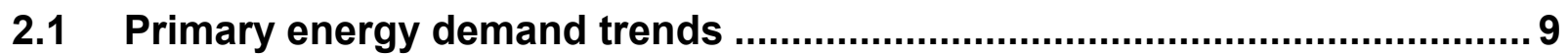

2.2 Biomass for energy demand trends ........................................................ 11

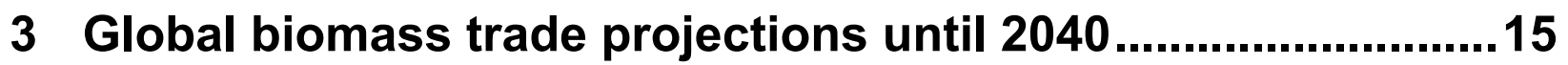

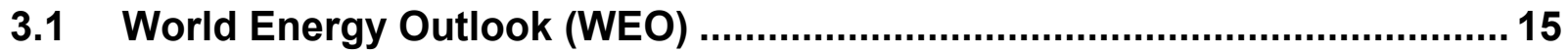

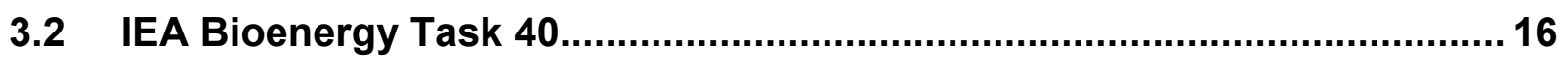

3.3 Comparison and cross-check with current trade flows............................. 18

4 European Union demand and trade projections .................... 19

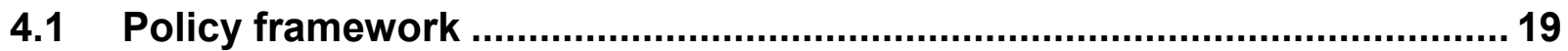

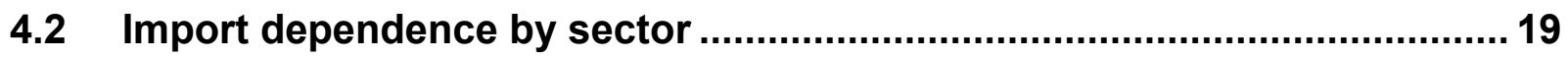

4.3 EU demand and trade projections until 2020............................................. 20

4.4 Demand across the main EU net importing markets by 2022, 2030, and

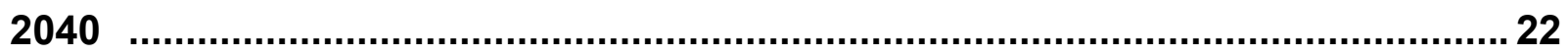

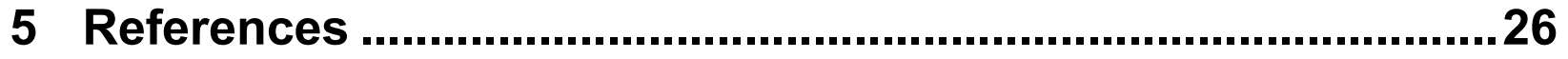

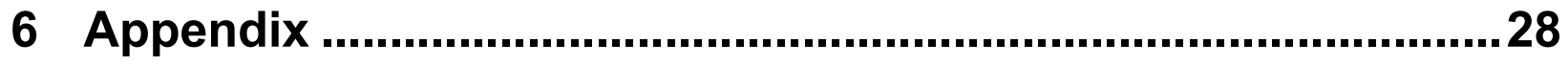

6.1 Bioenergy deployment levels and dynamics with land transformation in

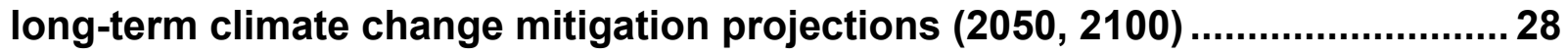

6.2 Background and calculation data ............................................................ 30

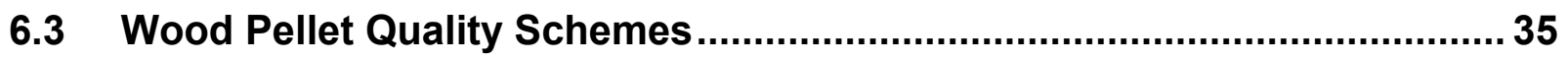




\section{Abbreviations}

ARA Amsterdam, Rotterdam, Antwerp (harbors)

BE Belgium

CIF Cost, Insurance, Freight

DK Denmark

DOE U.S. Department of Energy

EJ Exa-Joule $\left(10^{18}\right)$

EPA Environmental Protection Agency

EU European Union

GHG Greenhouse Gas

IEA International Energy Agency

MS Member State (of the EU)

Mtoe Million Tonnes of Oil Equivalent

Mtons Million (U.S. short) tons

$\mathrm{NL}$ the Netherlands

NREAP National Renewable Energy Action Plan

NW North-West

OECD Organisation for Economic Co-operation and Development

PJ Peta-Joule $\left(10^{15}\right)$

ppm Parts Per Million

RED Renewable Energy Directive 2009/28/EC

RES Renewable Energy Sources

RFS2 Renewable Fuel Standard (version 2010)

TJ Tera-Joule $\left(10^{12}\right)$

UK the United Kingdom

WEO World Energy Outlook (annual IEA publication)

$\mathrm{WP}_{\mathrm{e}} \quad$ Wood Pellet Equivalent (assumed energy content of $16 \mathrm{GJ} / \mathrm{ton}$ ) 


\section{Introduction}

\subsection{Project background and milestone context}

The development of a U.S. bioenergy market and ultimately 'bioeconomy' has primarily been investigated with a national focus. Limited attention has been given to the potential impacts of international market developments. Nevertheless, recent history, e.g., the liquid biofuel market, suggests that globalization may initially prove turbulent for a domestically focused industry (Lamers et al. 2011). Thus, there may be business/investment and policy risks, in particular volume and price target barriers given international feedstock competition. Understanding international market interactions and lessons learned by other nations will prove beneficial for the U.S. bioeconomy in a globally competitive environment.

The goal of this project is to advance the current State of Technology of a single biorefinery to the global level providing quantitative estimates on how international markets may influence the domestic feedstock supply costs. The intent is to reduce uncertainties regarding the development of the U.S. grower payment and logistics cost, and provide insight as to whether the cost (US $\$ 80$ per ton of feedstock delivered and US\$3 per gallon of gasoline equivalent) and volume targets for a U.S. biorefinery industry are at risk in an international market context.

The scope of the project is limited to feedstock that is currently available and new crops being developed to be used in a future U.S. bioeconomy including herbaceous residues (e.g., corn stover), woody biomass (e.g., pulpwood), and energy crops (e.g., switchgrass). The timeframe is set to the periods of 2022, 2030, and 2040 to align with current policy targets (e.g., the RFS2) and future updates of the Billion Ton data (DOE 2011).

This particular milestone delivers demand curves for generic woody and herbaceous feedstocks for the main (net) importing regions along the above timeframes. The data behind the demand curves will identify potential international competitors/markets for U.S. biomass supplies for feedstocks such as pulpwood, logging residues, corn stover, and switchgrass. The regional focus of the study is the European Union (EU), currently the largest export region of U.S. wood pellets. These wood pellets are predominantly derived from pulpwood and used in large-scale power plants in the United Kingdom, the Netherlands, Belgium, and Denmark (Goh et al. 2013). Pellets from herbaceous residues (e.g., wheat straw, shea nut) still have a limited market volume in this sector but have the potential to become a larger fraction in the future (e.g., due to woody biomass sustainability concerns) (Lamers et al. 2014a). Additionally, other major world regions are analyzed to put EU demand into perspective.

\subsection{Approach and outline}

Long-term global energy trends are usually derived via general or partial equilibrium models, taking a top-down approach across energy resources and markets. While these models are capable of incorporating various dynamic factors in international markets, including among others developments of gross-domestic product, carbon prices, land constraints, and energy policies. Their sector specific modeling in the short- and medium-run is less representative of actual industry trends. 
Such trends are more accurately covered in so-called bottom-up models, which explicitly focus on current industry status, production capacity within a certain sector, and sector trends in shorter timeframes. Also, they allow for a more detailed modeling of specific value chains, including transport costs and optimal logistical routes (e.g., Hoefnagels et al. 2014b).

Studies of both types will be reviewed for this analysis. Global bioenergy demand and trade developments will be derived via top-down model results. Detailed short- and medium-term trends for the focus region of this study, the EU market, will be detailed via data from bottom-up models.

In contrast to biomass resource assessments, future trade analyses are typically not feedstock specific. This implies that generic feedstock demand has to be broken down by sector (e.g., electricity production, transport, etc.) and assumptions have to be made with respect to the desired feedstock within the respective conversion pathways. These assumptions and data breakdowns are detailed in the respective sections.

The report provides global demand and trade projections before it specifically addresses EU demand and trade projections. Global biomass demand projections until 2040 are outlined in Section 2. Section 3 reviews global trade scenarios by 2040 based on top-down modeling efforts and compares them to current trade and industry developments. Section 4 details the EU market expectations and derives feedstock specific demand trends. 


\section{Global biomass demand trends until 2040}

Long-term climate change mitigation scenarios project bioenergy deployment levels between 100-300 EJ by 2050, with the range largely depending on the market readiness of carbon capture and storage technology and the long-term international atmospheric carbon concentration target (Chum et al. 2011, Clarke et al. 2014) (see Appendix for details). To derive mid-term energy demand trends for 2022, 2030, and 2040, current and proposed policies need to be evaluated to project bioenergy demand trends. Policy targets, including renewable energy shares, are relative goals requiring a projection of the respective reference (e.g., final energy consumption). Thus, feedstock demand trends need to be projected with respect to overall energy consumption trends. For these mid-term overall trends, we use the latest World Energy Outlook (WEO) data (IEA 2014). The WEO provides an accurate reflection of current and new policy trends in the mid-term, is updated annually and fully accessible with respect to country data and policy assumptions.

\subsection{Primary energy demand trends}

The WEO (IEA 2014) offers three distinct global scenarios (Figure 2): a continuation of current policies (Current Policies Scenario), a stringent policy scenario to stabilize atmospheric carbon concentrations to $450 \mathrm{ppm}$ (450 Scenario), and a scenario that takes into account policies and implementing measures affecting energy markets that had been adopted as of mid-2014, including relevant policy proposals, although specific implementation measures may have yet to be fully developed (New Policies Scenario). The New Policies Scenario is the central WEO scenario and matches the EU policy assumptions of other models relevant to this report.

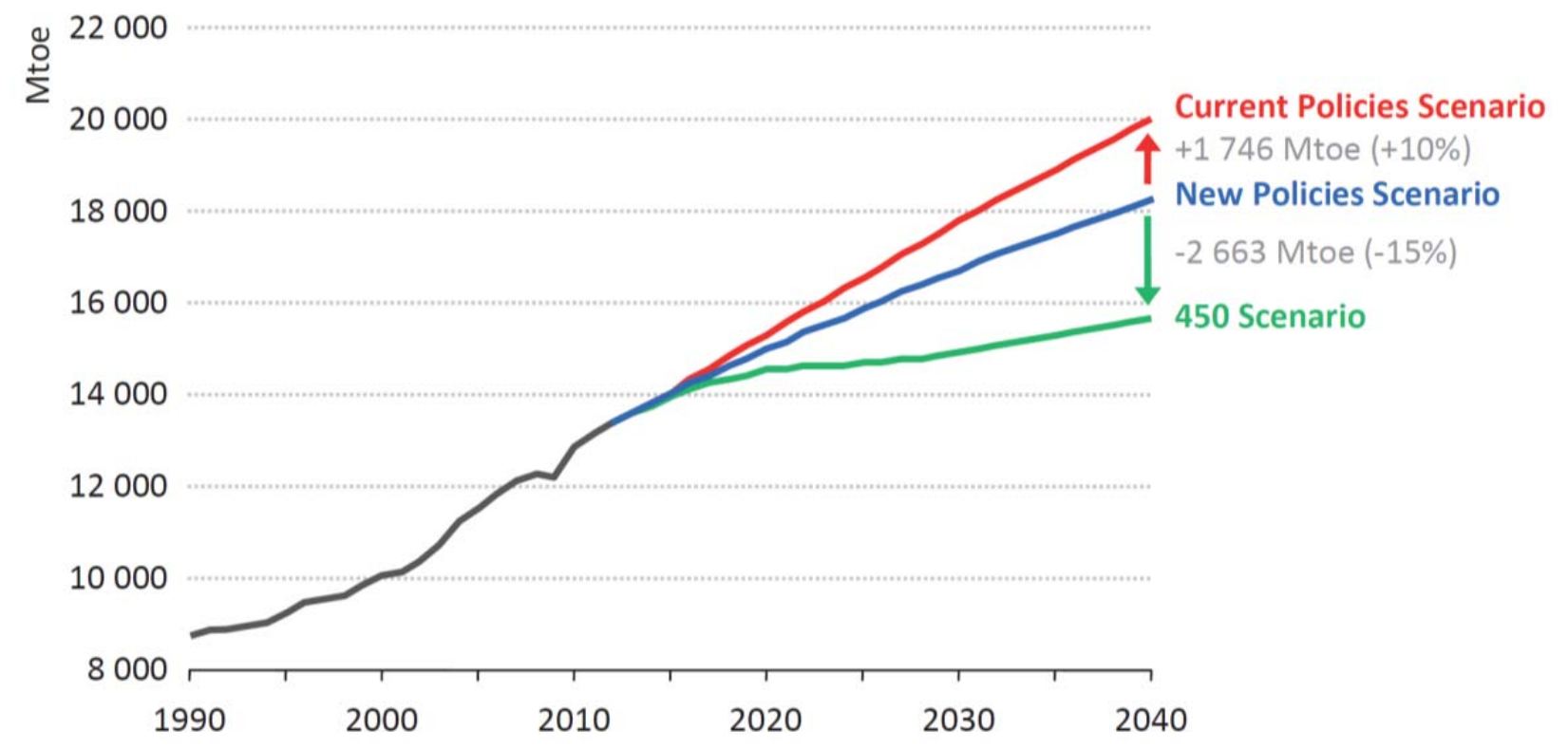

Figure 2. World total primary energy demand by scenario (IEA 2014).

Note: 10,000 Mtoe equal 419 EJ or 397 PBtu. 
A summary of the policies and trends for the key global demand regions represented in the New Policies Scenario are shown in Table 1.

Table 1. Overview of policies and trends in the New Policies Scenario.

\begin{tabular}{|c|c|}
\hline Country/Region & Policies and Trends \\
\hline U.S. & $\begin{array}{l}\text { - Environmental Protection Agency's (EPA) Clean Power Plan, aiming to cut power } \\
\text { - } \text { sector emissions in } 2030 \text { by } 30 \% \text { (relative to } 2005-l e v e l s \text { ) } \\
\text { - Dontinuation of the Renewable Fuel Standard (RFS2) } \\
\text { - Demantinuation of the biodiesel producer tax credit } \\
\text { drastically: natural gas dominates the fuel mix after 2030, coal loses market shares } \\
\text { to renewable energy sources (RES). }\end{array}$ \\
\hline European Union & 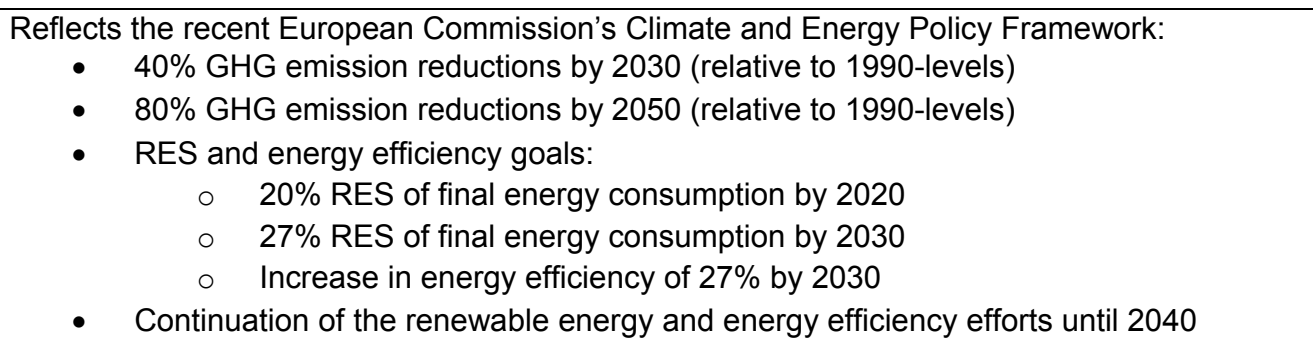 \\
\hline China & $\begin{array}{l}\text { - Reflects the Action Plan for Prevention and Control of Air Pollution to reduce coal } \\
\text { consumption and increase the use of non-fossil energy resources. } \\
\text { - Overall demand increase by } 44 \% \text { until } 2040\end{array}$ \\
\hline India & $\begin{array}{l}\text { - } \quad \text { New vehicle fuel-economy standards of } 4.8 \text { litres per } 100 \text { kilometres by 2021-2022 (a } \\
15 \% \text { improvement) } \\
\text { - } \quad \text { Subsidies for electric and hybrid vehicle purchases } \\
\text { - } \quad \text { Increase in the ethanol blending mandate } \\
\text { - } \quad \text { Current fuel ethanol blending requirement of } 5 \% \text { raised to } 10 \% \text { in the short-term } \\
\text { - } \quad \text { Other trends: Energy demand more than doubles until } 2040, \text { coal use for power } \\
\text { continually increases, use of fuelwood in traditional uses declines. }\end{array}$ \\
\hline Japan & $\begin{array}{l}\text { Takes into account the New Strategic Energy Plan: } \\
\text { - Most idled nuclear plants steadily return to service after receiving regulatory } \\
\text { approval. } \\
\text { Increasing investment in non-hydro renewable energy sources (photovoltaics in } \\
\text { particular) }\end{array}$ \\
\hline Russia & $\begin{array}{l}\text { - Energy demand grows by } 11 \% \text { but the fuel mix remains stagnant due to a limited } \\
\text { policy push }\end{array}$ \\
\hline Brazil & - $\quad$ Strives to become the world's main bioethanol supplier \\
\hline $\begin{array}{l}\text { Sub-Saharan } \\
\text { Africa }\end{array}$ & - More than half of the energy demand increase occurs in Nigeria and Southern Africa \\
\hline
\end{tabular}


In the New Policies Scenario world primary energy demand increases by $37 \%$ from 13,361 Million tonnes of oil equivalent (Mtoe) (559 EJ) in 2012 to 18,290 Mtoe (766 EJ) in 2040. The largest absolute demand growth is expected in China and India (Figure 4). China is expected to be the dominant force behind global demand growth until 2020-2025, accounting for more than one-third of the total increase. The period after 2025 (until 2040) is dominated by energy demand growth in India. Per sector, the largest demand increase occurs in power generation, followed by industrial demand. In the New Policies Scenario global greenhouse gas (GHG) emissions rise by $20 \%$ until 2040 , consistent with a global mean temperature increase of $3.6^{\circ} \mathrm{C}$.

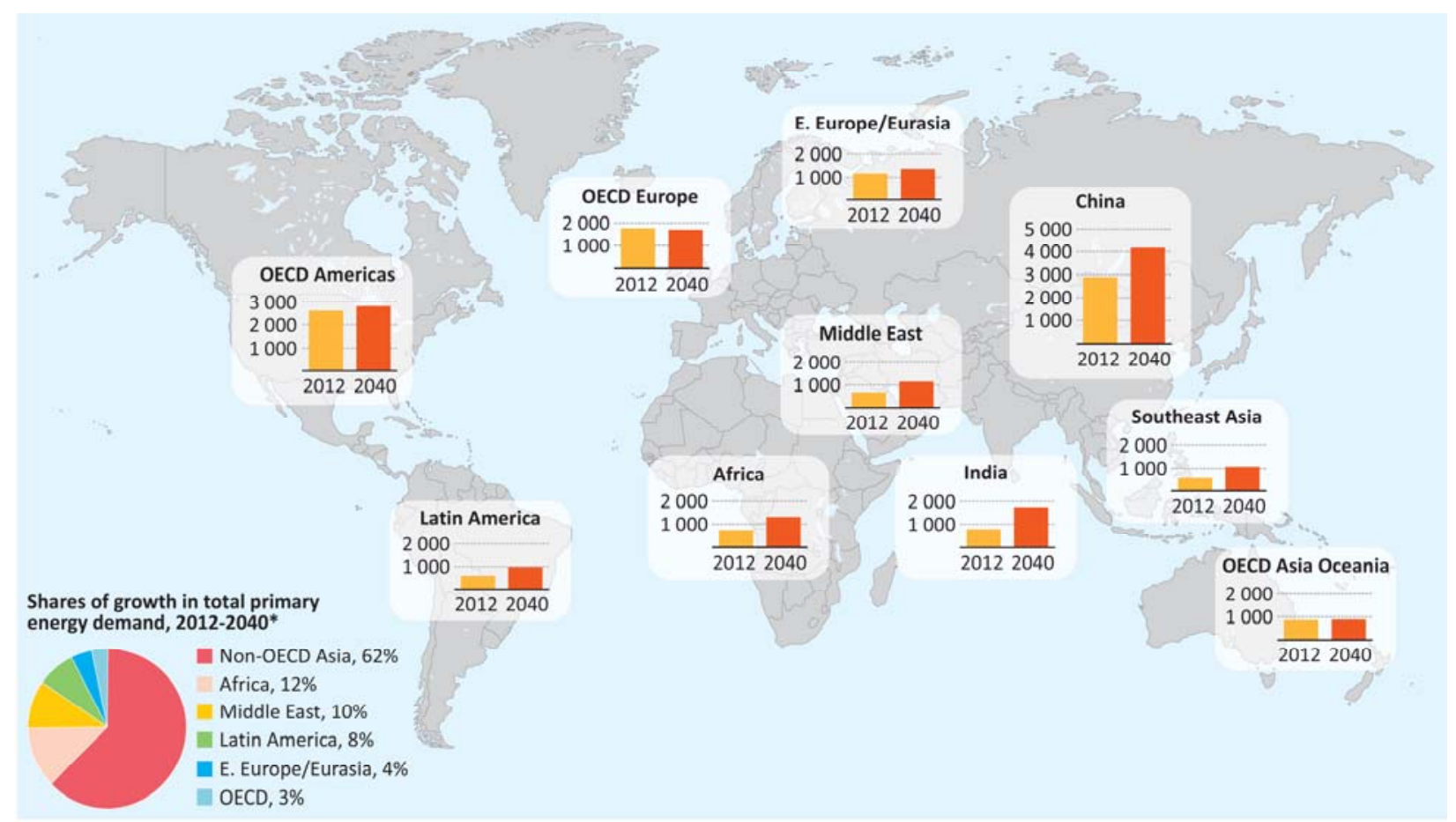

Figure 3. Primary energy demand by region in the New Policies Scenario in Mtoe (IEA 2014).

OECD: Organisation for Economic Co-operation and Development

\subsection{Biomass for energy demand trends}

The mobilization of RES is less limited by the availability of resources than it is by geographical and economic constraints (IEA 2014). In the New Policies Scenario, the output of modern biomass for energy expands across all sectors, while the use of traditional biomass is projected to decline until 2040 (Figure 4). The majority of new biomass conversion facilities are projected to occur in the power generation sector (Figure 4). This trend is driven by a combination of government policies and technological advances (particularly combined heat and power generation), which are expected to lower production costs. In addition, increasing fossil fuel prices and higher carbon prices create a competitive market situation for bioenergy power generation in many countries.

With respect to transport, biofuels are projected to be mainly used for road transport with limited application in the aviation industry. Advanced biofuels are expected to be commercialized as of 
2020, inked to further improvements in harvest votumes. The share of advanced biofuets in total global biofuel consumption increases from currently less than $1 \%$ to about $20 \%$ by 2040 (1.83 EJ) (IEA 2014). The regional dominance in the consumption of biofuels will still be the U.S., the EU, and Brazil. Nevertheless, China and India are expected to increase their demand until 2040.

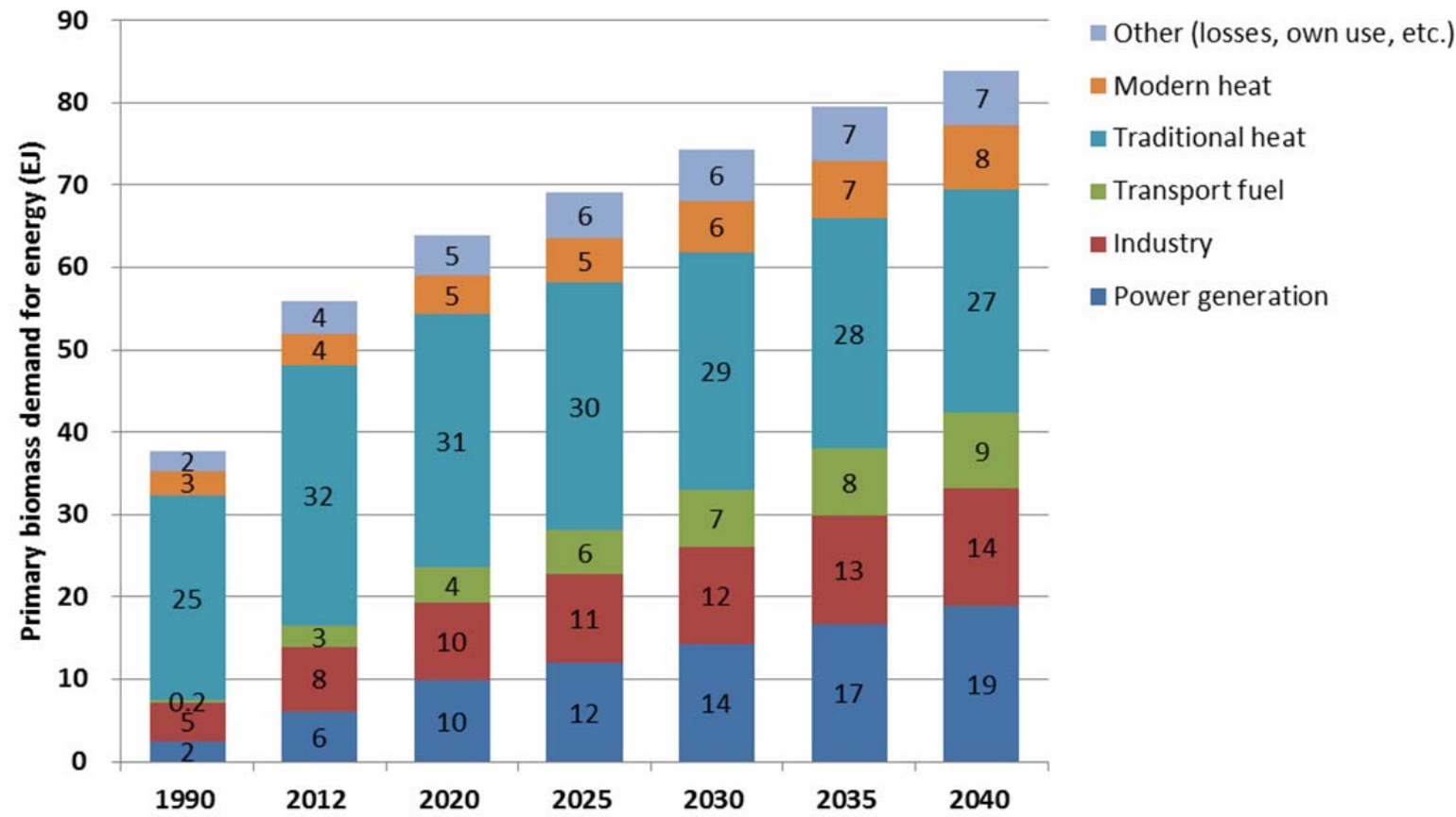

Figure 4. Global primary biomass demand for energy in the New Policies Scenario by sector (Data: IEA 2014).

As shown in Figure 5, the largest absolute primary biomass demand increases until 2040 are expected to occur in the U.S. (4.58 EJ), the EU (3.72 EJ), and China (2.34 EJ), followed by Brazil $(2.27 \mathrm{EJ})$ and India (1.89 EJ). Russia is expected to triple, Japan to almost double its primary biomass demand from 2012 to 2040; albeit their total national demand will still be less than 1 EJ by 2040.

Figure 5 also highlights the different sectorial demand trends between the selected countries. The strongest push for biofuels in the transport sector is projected for the U.S., followed by Brazil, the EU, and China. The largest demand increase for biomass in the power sector will be by far in China, followed by the U.S. and India.

Based on data presented in Figure 5, we derive a first feedstock demand estimate by percentage assumptions of three feedstock types per sector demand (Figure 6) (see Appendix for calculation details). Across the U.S., EU, Japan, and Russia, woody biomass can be assumed to cover the majority of the demand in the power generation, industry, and buildings sector due to combustion technology and local resource availability. Herbaceous biomass will cover the remaining share and the majority of the demand for advanced transport fuels. Woody biomass shares in the transport sector increase towards 2030 and 2040. 
$=$

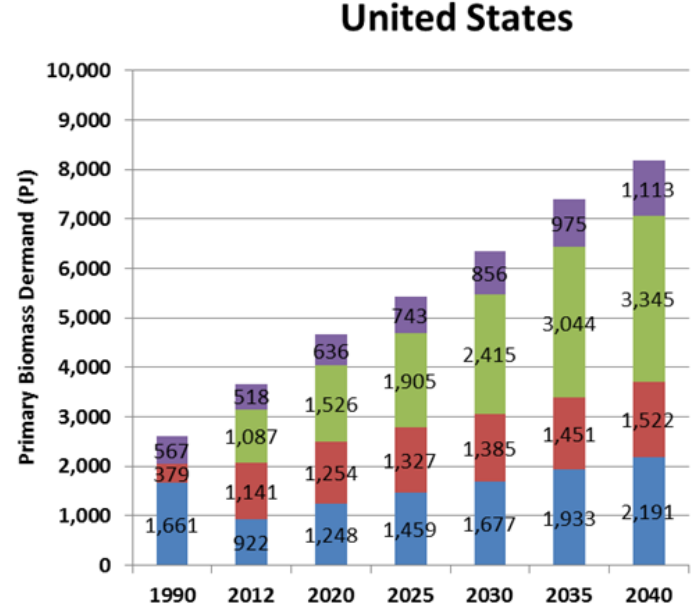

Japan

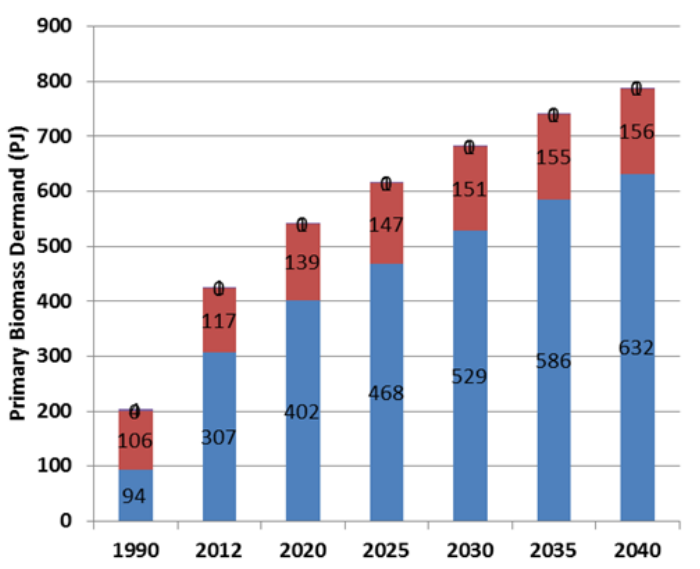

China

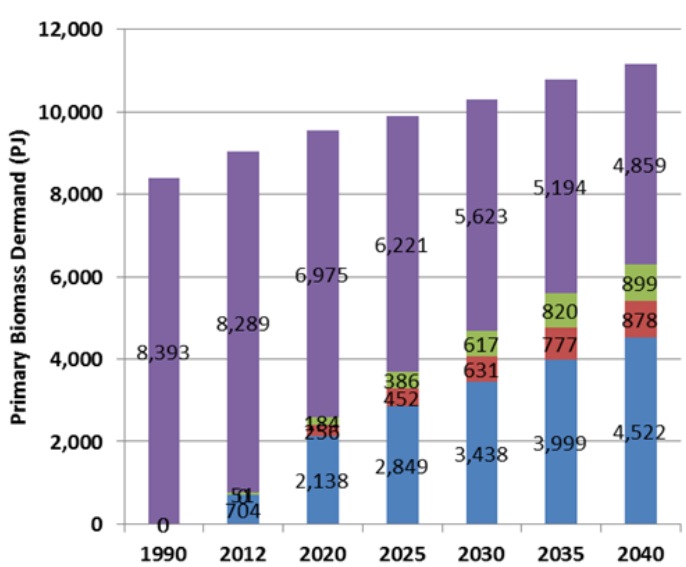

a Buildings

- Transport

- Industry

nower generation

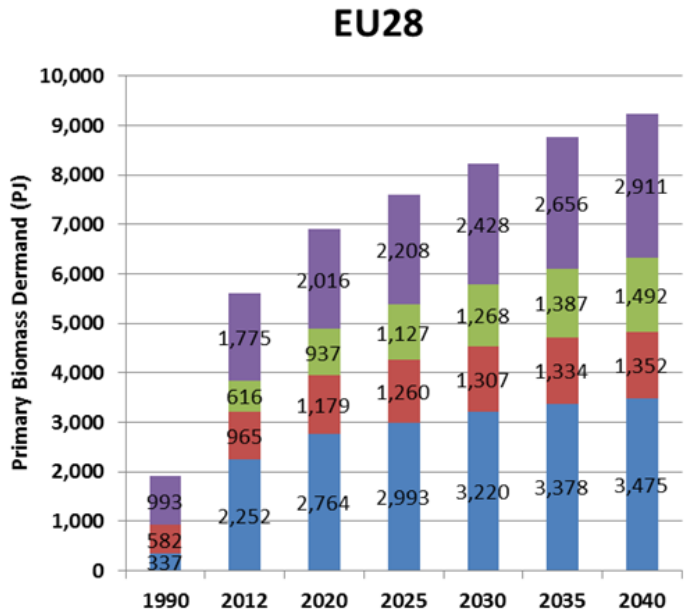

Buildings

- Transport

- Industry

Power generation

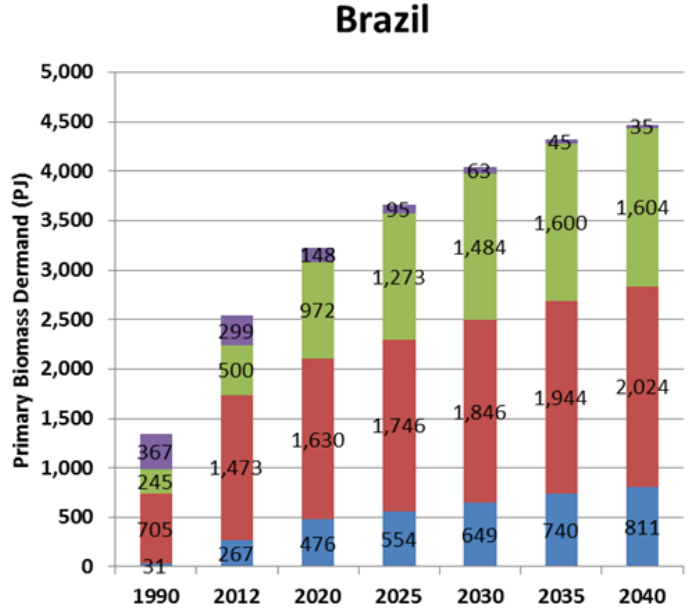

\section{India}

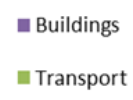

Industry

Power generation

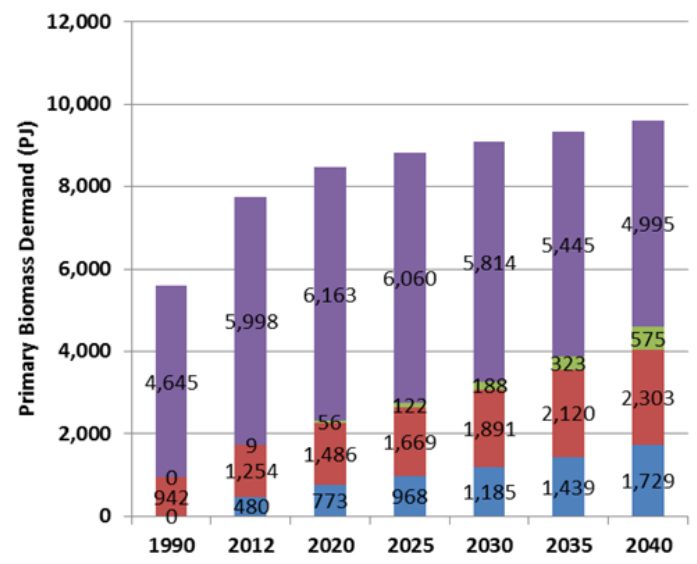

Figure 5. Primary biomass demand for energy in the New Policies Scenario for selected countries (Data: IEA 2014). 
Power generation across Asian makets is dominated by fluidized bed bollers, accepting a wider range of feedstock in homogeneity, quality, and size. Also, the regional feedstock availability in China and India is largely agricultural residues. Thus, the share of herbaceous material is assumed to dominate. Brazilian power generation, especially in industry is also largely based on herbaceous residue material.
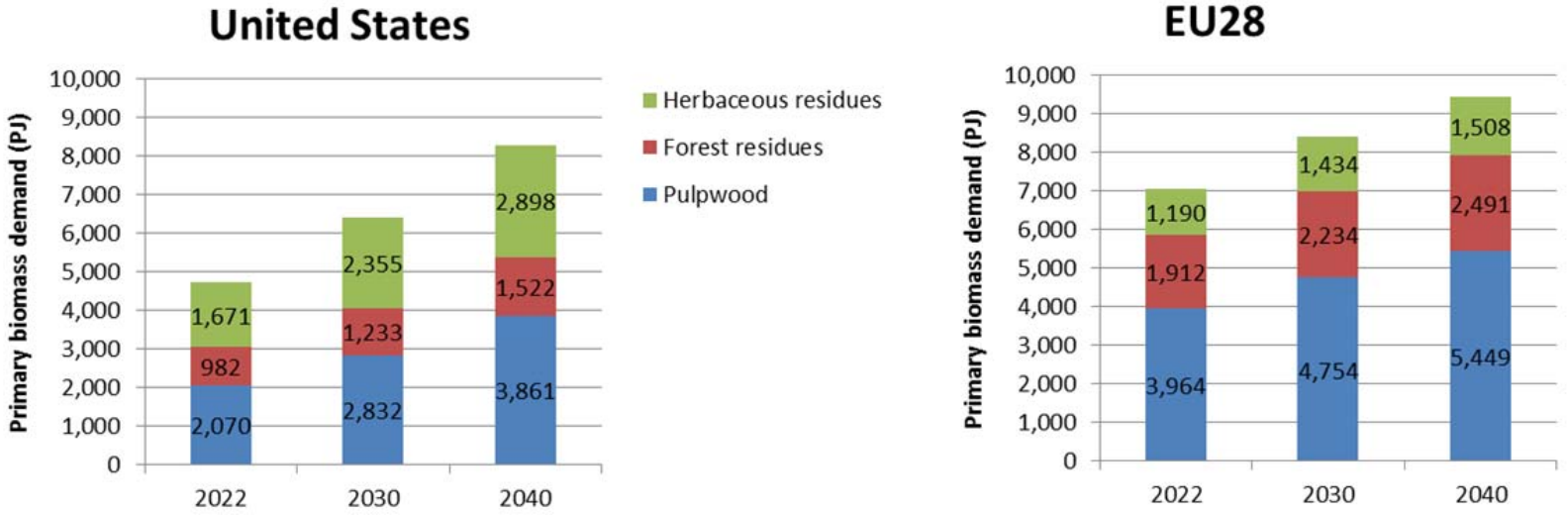

\section{Japan}
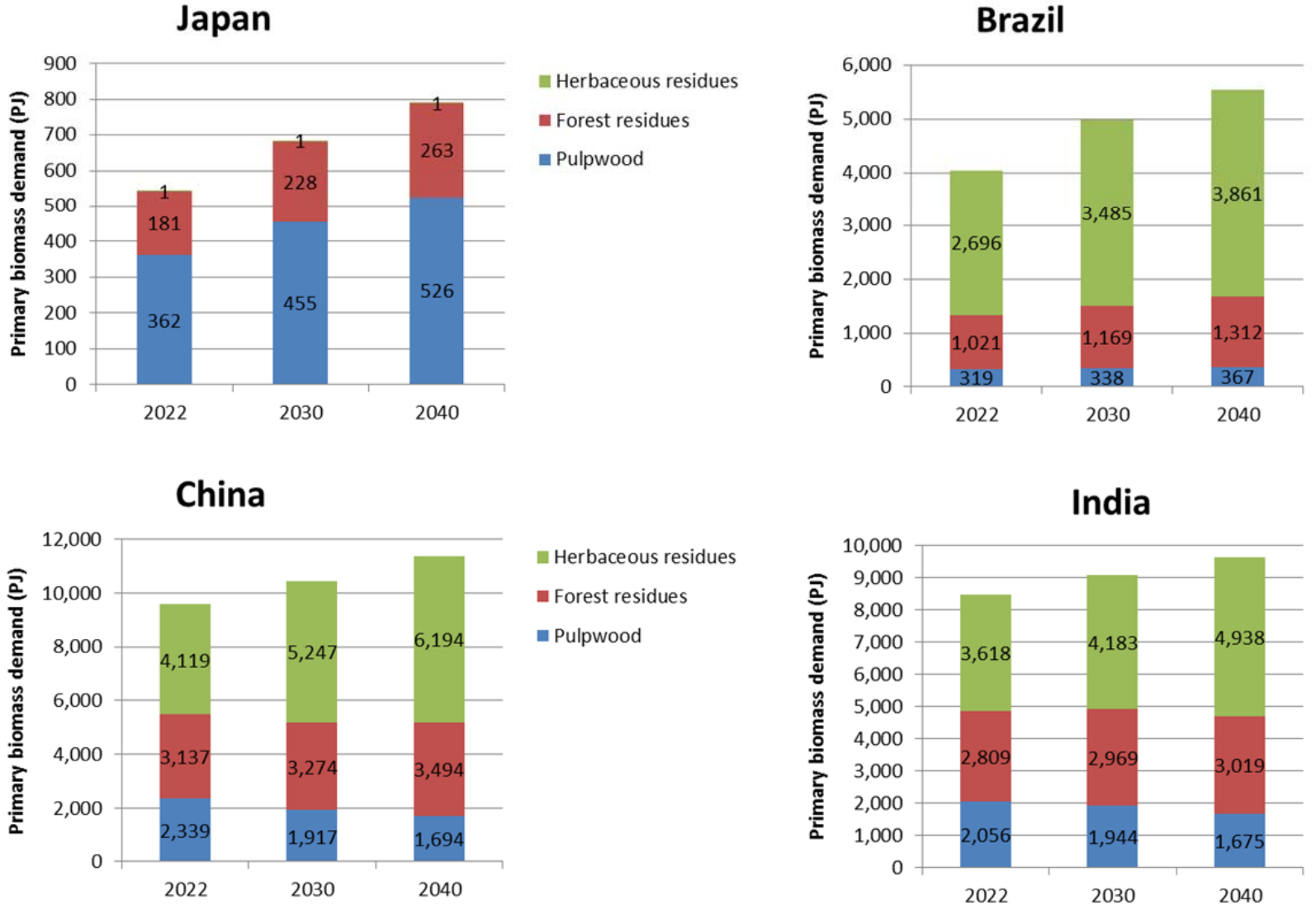

Figure 6. Feedstock demand estimate in selected countries/regions. 


\section{Global biomass trade projections until 2040}

There is a limited range of forecasts with a focus on biomass for energy trade. Long-range scenarios of global general equilibrium models include bioenergy trade only implicitly (in terms of resource allocation) but do not provide data output on specific trade flows. At the same time, their high-level projections do not reflect current industry status, production capacity within a certain sector, or sector trends in shorter timeframes. Such trends are more accurately covered by bottom-up models (e.g., BIT-UU).

In disparity to other global equilibrium models and forecasts, the WEO (IEA 2014) has added a bioenergy trade module in its 2012 update and offers specific trade information. This section summarizes recent research on trade flow projections including the WEO and findings of an IEA Bioenergy Task 40 study comparing different models (bottom-up and top-down) with respect to international bioenergy trade (Kranzl et al. 2014).

\subsection{World Energy Outlook (WEO)}

The WEO projects a predominantly domestic use of biomass resources, linked to the assumption that most policies supporting the increased use of bioenergy occur in regions with ample biomass resources (e.g., the U.S. and Brazil) (IEA 2014). Furthermore, the WEO considers transport costs a significant barrier to a continuation of international trade over the use of local resources. The report projects trade in transport biofuels to plateau in the early 2030's due to an increased domestic production of advanced biofuels. In the New Policies Scenario net international trade of biomass for energy is expected to be around $3.35 \mathrm{EJ}$ (80 Mtoe) or $4 \%$ of total primary biomass demand by 2040 (Table 2).

Table 2. International biomass trade volumes of selection countries/regions in the New Policies Scenario (Data: IEA 2014).

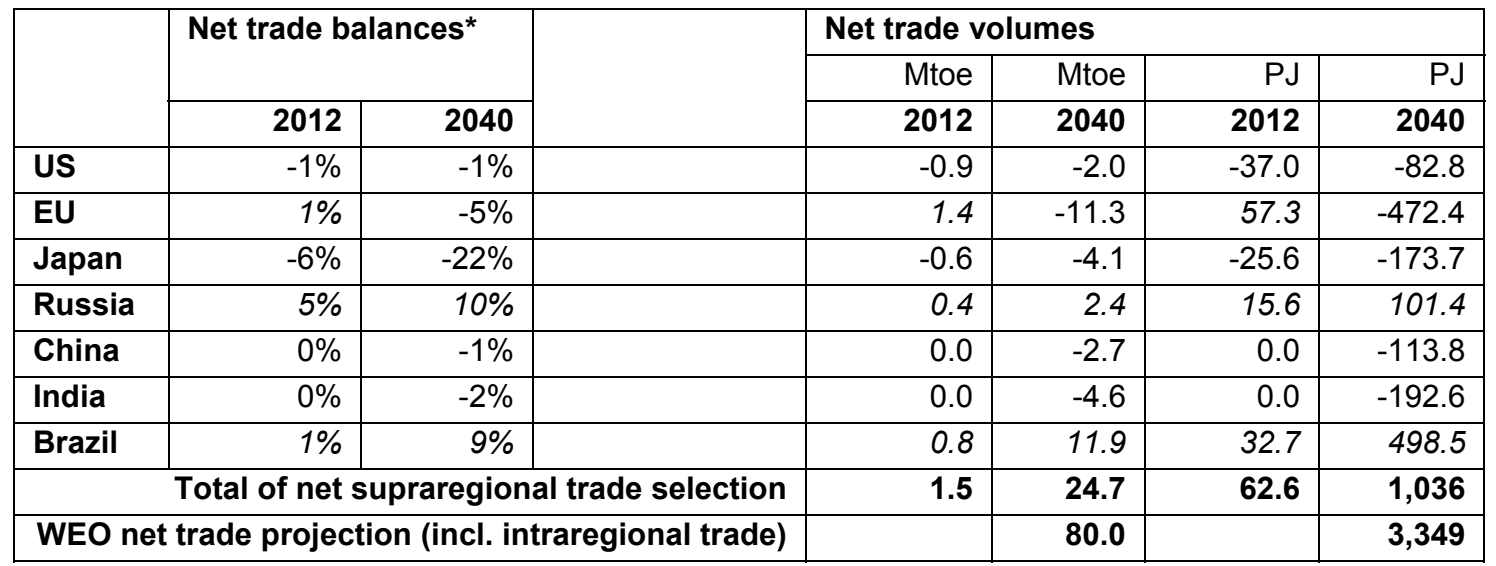

${ }^{*}$ Note: Negative balances indicate net imports. Net imports are calculated as a share of total primary biomass demand. Net exports are calculated as a share of total production.

Net exporters of biomass in the long-term are expected to be Brazil and Russia (plus SouthEast Asia) (Table 2). Within the WEO projections, Brazil establishes itself as the main supplier for (sugarcane derived) fuel ethanol, exporting to the EU and North America. Russia continues to export forest biomass to the EU and Asia. South-East Asia becomes the key source for 
-biomass demand atong the Pacific-Rim. The EU continues to expand its international demand and remains the largest net importer until 2040 (Table 2). Other key importing regions include China, India, Japan, and to an increasing extent the U.S. The underlying reasoning is that, over the projection period, the demand for biofuels in the U.S. outstrips local supply, which will be met predominantly by imports from Brazil.

\subsection{IEA Bioenergy Task 40}

A wider comparison of different energy sector models and their future bioenergy trade projections was done by Kranzl et al. 2014. The authors selected three global and partial equilibrium models (IMAGE/TIMER, POLES, and the Global Forest Product Model GFPM) from a list of 28 different models and/or studies. The scenarios investigated were split in two groups based on their respective policy targets.

The set of ambitious scenarios comprises of policy measures aimed to achieve a $450 \mathrm{ppm}$ atmospheric carbon concentration level or a carbon price of at least US\$100 per metric tonne of $\mathrm{CO}_{2}$. All other scenarios, assuming higher atmospheric carbon concentrations, lower carbon prices, or both are grouped under the set of moderate scenarios. It should be noted that the models investigated by Kranzl et al. 2014 (with the exception of GFPM) are typically used to project long-term energy (and carbon) trends, up to the year 2100. The respective scenarios until 2040 should therefore be interpreted with caution.

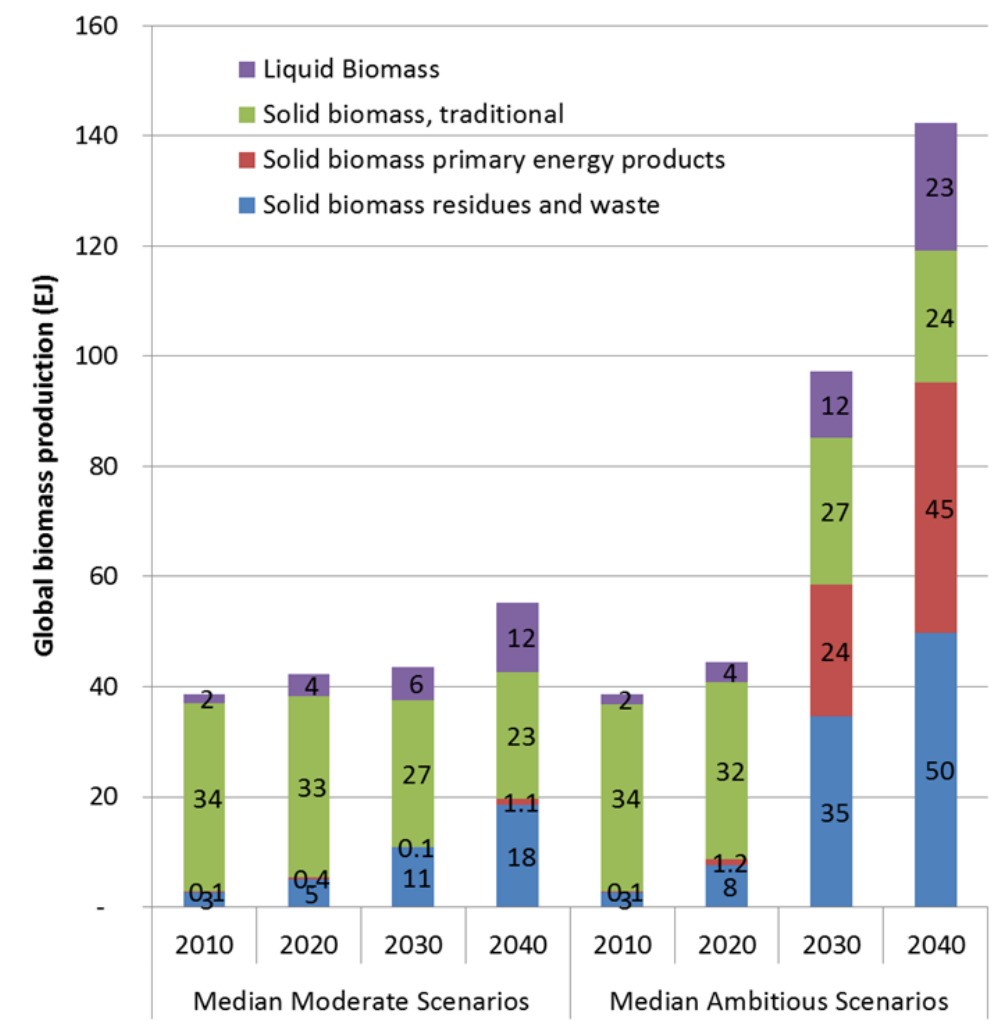

Figure 7. Global biomass production across IMAGE/TIMER and GFPM scenarios (Data: Utrecht University). 
In-ine with projections by IEA 2014, Kranzt etal. 2014 find that total production and demand of biomass for energy are to increase significantly while the demand mix will shift away from traditional to modern applications (Figure 7).

In the ambitious as well as the moderate scenarios, the main exporting regions are expected to include Russia and former Soviet Union states, Canada, South America, Africa, and Oceania. The key importing region will remain to be Western Europe while China and India grow in importance. The U.S. is projected to be a net exporting region for solid biomass until 2040, while its liquid trade balance is projected to be clearly negative. Nevertheless, the total imports of liquid biofuels to Western Europe and the U.S. are projected to decline after 2030. The large range in the demand and thus import/trade projections across South-East Asia, China, and India reveal stark contrasts between the moderate and ambitious trade scenarios after 2030 (Figure $8)$.

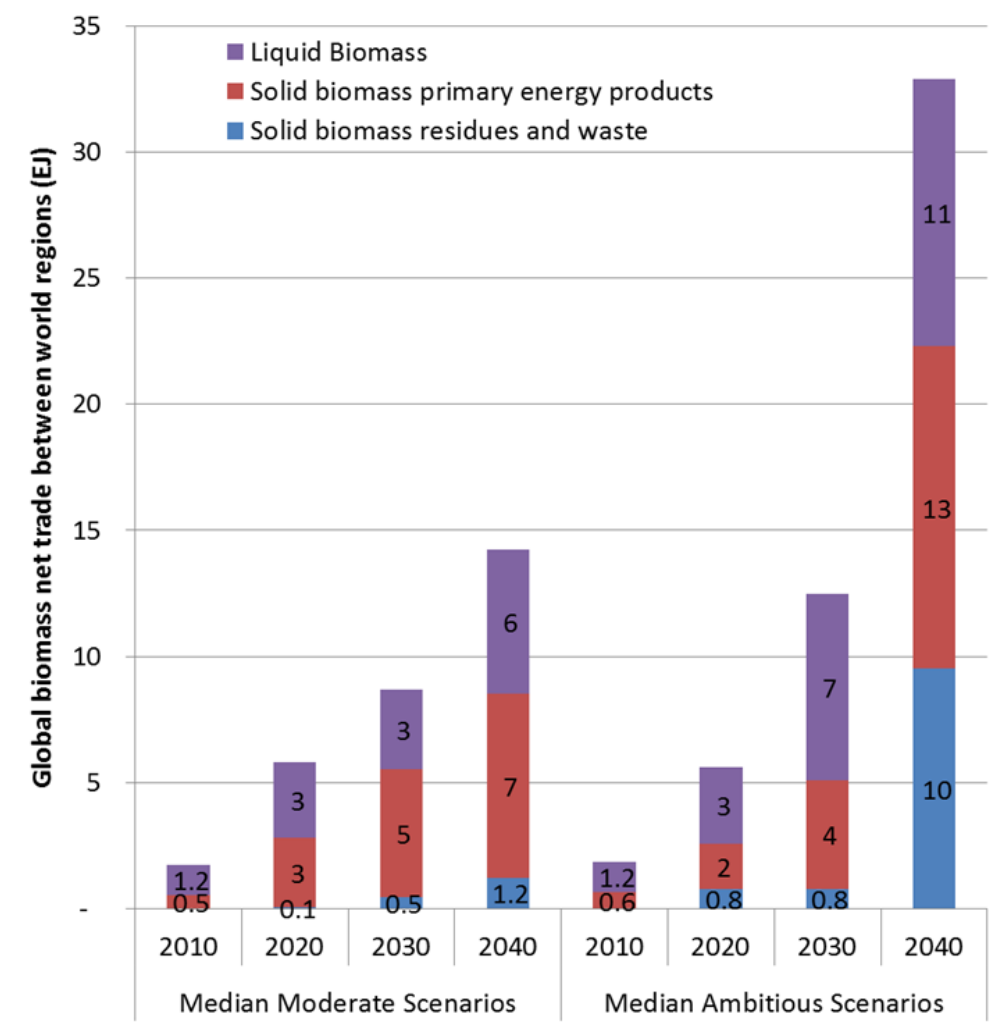

Figure 8. Global biomass net trade between regions across IMAGE/TIMER and GFPM scenarios (excluding intraregional trade) (Data: Utrecht University).

Note: Models investigated by Kranzl et al. 2014 do not project trade with traditional biomass. 


\subsection{Comparison and cross-check with current trade flows}

A direct comparison between the above models in Table 3 shows that the WEO primary biomass demand projections by 2040 are in-between projections for biomass deployment levels in Kranzl et al. 2014. The solid biomass net trade projections by 2040 however differ greatly between the publications (Table 3). This appears to be predominantly related to the central WEO assumption that local biomass supply is cost competitive to imports due to reduced transport costs. Continued mobilization of local biomass resources, including improved logistics and distributed preprocessing centers (Hess et al. 2009), may eventually support this hypothesis. This assumption however does not hold true under current and expected market conditions, and thus much larger trade flows may occur until 2022 and 2030 . Studies on the future EU biomass trade balance project that local biomass resources tend to be more costly than imports (Hoefnagels et al. 2014a, Lamers et al. 2014a). This is discussed in detail in the following section.

Table 3. Overview of models, scenarios, and results.

\begin{tabular}{|c|c|c|c|c|}
\hline Model and Scenario & $\begin{array}{l}\text { Primary biomass } \\
\text { demand by } 2040 \\
\text { (EJ) }\end{array}$ & $\begin{array}{l}\text { Global biomass } \\
\text { deployment by } \\
2040 \text { (EJ) }\end{array}$ & $\begin{array}{l}\text { Global biomass } \\
\text { trade by } 2040 \\
\text { (EJ) }\end{array}$ & $\begin{array}{l}\text { Global biomass } \\
\text { trade by } 2040 \\
\text { (\% of production) }\end{array}$ \\
\hline WEO 450 ppm & 105.72 & & & \\
\hline WEO New Policies & 83.82 & & 3.35 & $4 \%$ \\
\hline WEO Current Policies & 80.93 & & & \\
\hline $\begin{array}{l}\text { Kranzl et al. 2014: Median } \\
\text { moderate scenarios* }\end{array}$ & & 55.22 & 14.24 & $26 \%$ \\
\hline $\begin{array}{l}\text { Kranzl et al. 2014: Median } \\
\text { ambitious scenarios* }\end{array}$ & & 142.43 & 32.91 & $23 \%$ \\
\hline $\begin{array}{l}\text { IPCC scenario reviews } \\
\text { (Chum et al. 2011, Clarke } \\
\text { et al. 2014) }\end{array}$ & & $100-300$ & $\mathrm{n} / \mathrm{a}$ & \\
\hline
\end{tabular}

The same would apply to the mobilization of local biomass resources for export. As discussed in Kranzl et al. 2014, a cross-check with current trade flows and main trading regions indicates that in the mid-term, the suggested main exporting regions will be limited to current main exporting regions. These include the U.S. and Canada for solid biomass and Brazil for liquid biofuels (Goh et al. 2013, Lamers et al. 2014b, Lamers et al. 2014c). Russia has so far not been able to mobilize significant volumes of woody biomass for export on a large-/country-scale, although some individual, larger projects exists (e.g., the Vyborgskaya wood pellet plant in NW Russia and trade in Eastern Russia with Asian States). Despite their large technical biomass potential (van Vuuren et al. 2009, Beringer et al. 2011, Schueler et al. 2013), Latin America, Africa, and Oceania do not export any significant volumes of solid biomass at the moment, and it is highly unlikely that sufficient investments in infrastructure will be realized in order to mobilize large volumes by 2030 from these regions in the medium-term. 


\section{European Union demand and trade projections}

\subsection{Policy framework}

The Renewable Energy Directive (RED) 2009/28/EC prescribes a 20\% share of RES in final energy consumption across the EU Member States (MS) by 2020. The pathway to this goal is detailed via the individual MS' National Renewable Energy Action Plans (NREAP), written in 2010, providing the technology and sector trajectories including the respective policy frameworks. According to the NREAPs, biomass for electricity production will ramp up to 825 PJ, heating and cooling will supply around 3,758 PJ, and biofuels about 1,208 PJ to the target by 2020 . Woody and herbaceous biomass are expected to contribute $90 \%$ to the heating and cooling target, $68 \%$ to biopower, and $9 \%$ to the transport fuels target by 2020 . While these projections appear very specific, the trajectories of the individual MS may not be fully aligned.

The policy goals beyond 2020 have been put forward in October 2014, when the European Commission announced its Climate and Energy Policy Framework, committing itself to a mandatory $27 \%$ RES target in final energy consumption by 2030 , plus a $27 \%$ increase in energy efficiency over the same timeframe (Table 1).

\subsection{Import dependence by sector}

The largest share of the EU solid biomass demand is for residential heating, the majority of which is supplied locally (e.g., via private forest smallholders) or traded from within the EU. Intra-EU trade for fuelwood, wood pellets, wood chips, and waste wood is significant. It made up about two thirds of the total global solid biomass trade by 2010 (Lamers et al. 2012).

The EU has been a net importer for wood pellets and wood chips for years. As global comparisons reveal, it has actually attracted most of the international trade streams over the past decade (Goh et al. 2013, Lamers et al. 2014b). The predominant EU market for these imports is the industrial sector, i.e., large-scale $\left(>5 \mathrm{MW}_{\mathrm{el}}\right) \mathrm{co}$ - and mono-firing heat and power installations. Due to the expected demand increase under current policy projections and limited regional resources (i.e., land constraints and time constraints to increase productivity levels), the EU is expected to remain a net importer for these feedstock types until 2040.

The key demand regions within the EU for this feedstock are large-scale heat and power stations across North-West (NW) Europe, including Belgium (BE), Denmark (DK), the Netherlands (NL), and the United Kingdom (UK). The Italian market is the fifth largest importer of wood pellets for the residential heating and medium-scale heat and power sector $\left(<5 \mathrm{MW}_{\mathrm{el}}\right)$. The primary sourcing regions for EU wood pellet imports are (in order of importance) the U.S., Canada, and NW Russia. The U.S. overtook Canada in total export volumes to the EU in 2012 (Lamers et al. 2014b). Figure 9 shows the export volume developments for the U.S. by export market in 2012 and 2013. The UK is the primary destination, having tripled its imports from the U.S. between 2012 and 2013 and accounting for $59 \%$ of total exports. Currently the U.S. wood pellet production capacity (predominantly for export) is around 6 Mtons. About 4.5 Mtons are expected to be exported to the EU in 2014. 


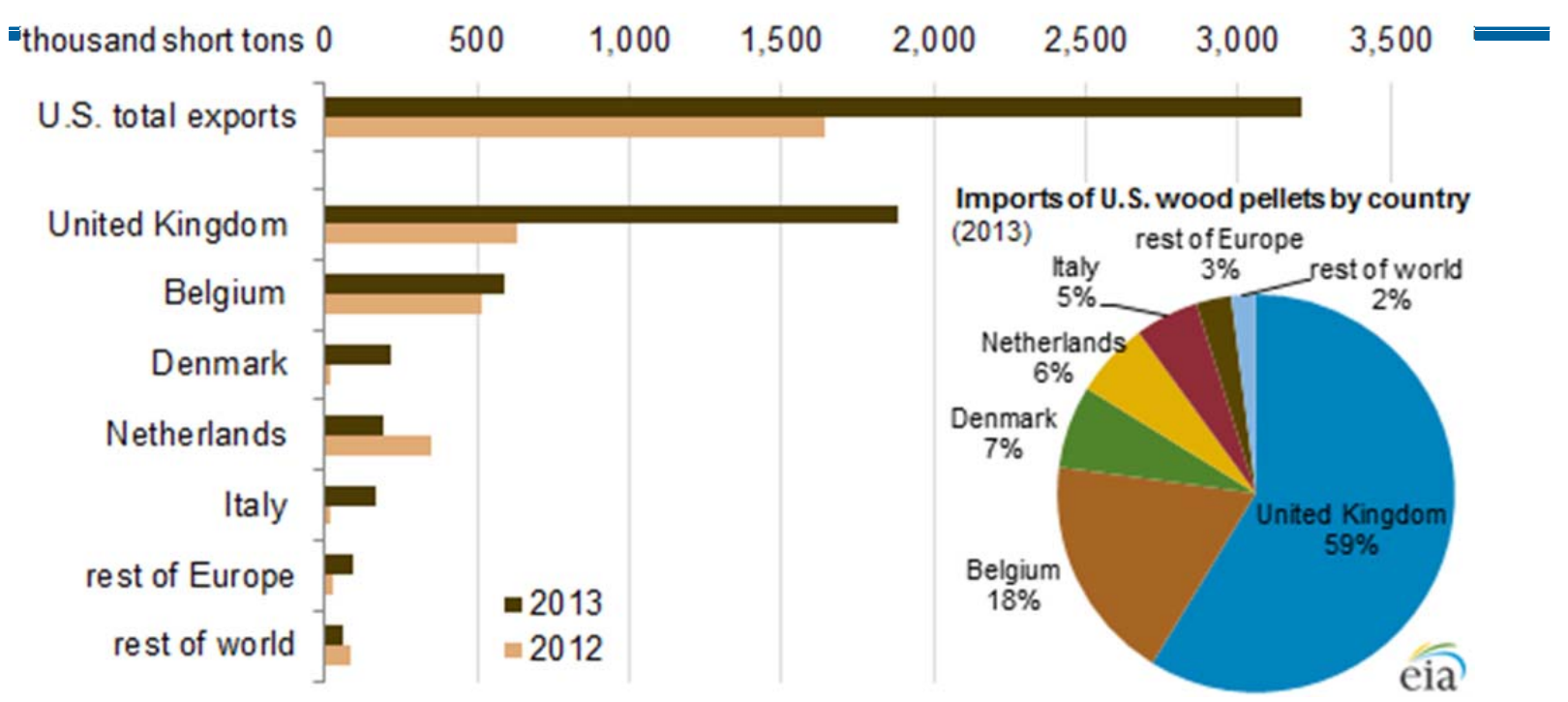

Figure 9. U.S. wood pellet exports by destination in 2012 and 2013 (Source: Energy Information Administration)

\subsection{EU demand and trade projections until 2020}

A detailed assessment of solid biomass trade developments towards the EU until 2020 was done by Lamers et al. 2014a. The authors designed and calibrated a bottom-up global trade model with a particular focus on volumes destined for large-scale heat and/or power facilities in NW Europe, including BE, DK, NL, UK (and Germany). To account for potential future sustainability legislation, the authors modeled four different supply scenarios for intra- and extraEU solid biomass streams, representing varying sustainability requirements. The analysis covers wood pellets and herbaceous (residue) pellets plus palm kernel shells.

The bottom-up analysis detailed wood pellet market developments with a specific focus on production and export to the EU. The herbaceous residue streams were limited to the top global producing regions with an export oriented agriculture sector to provide the necessary logistical basis for export to Europe. The EU demand by 2020 was based on EU policy and NW Europe industry expectations (as of July 2013). To appropriately model international competition for tradable woody biomass by 2020, the authors included demand by South Korea and Japan, in the order of $70 \mathrm{PJ}$ and $53 \mathrm{PJ}$ respectively (based on local demand projections minus expected available domestic supply by 2020).

A key finding is that the individual countries have a heterogeneous import dependency (Figure 10). The UK and the NL rely to over $50 \%$ on imports from either other EU MS or outside Europe. This is primarily linked to the limited domestic supply and the highly accessible infrastructure. Both countries have a sophisticated network of open sea and inland harbors and waterways that often allow imports directly to the power plants. Denmark has a similar situation with respect to woody biomass. However, it also has a large amount of low-cost agricultural residues that make up about $1 / 3$ of the total supply mix (Figure 10). 
Across the scenarios, domestic biomass resources are-mobilized first until an average-supply cost of US $\$ 113$ per ton ${ }^{1}$ including preprocessing (100€ per metric tonne wood pellet equivalent $\left.W P_{e}\right)$. These fractions are often associated with residential woody biomass use for heat (fuelwood and wood chips). After this point, intra-EU imports start to appear in the supply portfolios until about US\$136 per ton CIF/ARA ${ }^{2}$ (120€/tonne WP $)$. Following, supply portfolios are dominated by extra-EU imports; especially those of import dependent countries. By feedstock, intra- and extra-EU pellet import volumes typically follow the sequence of pulpwood, forest residues, herbaceous residues, and short-rotation coppice. This reflects supply costs as well as sector preferences for (high quality) woody material in heat and power production.
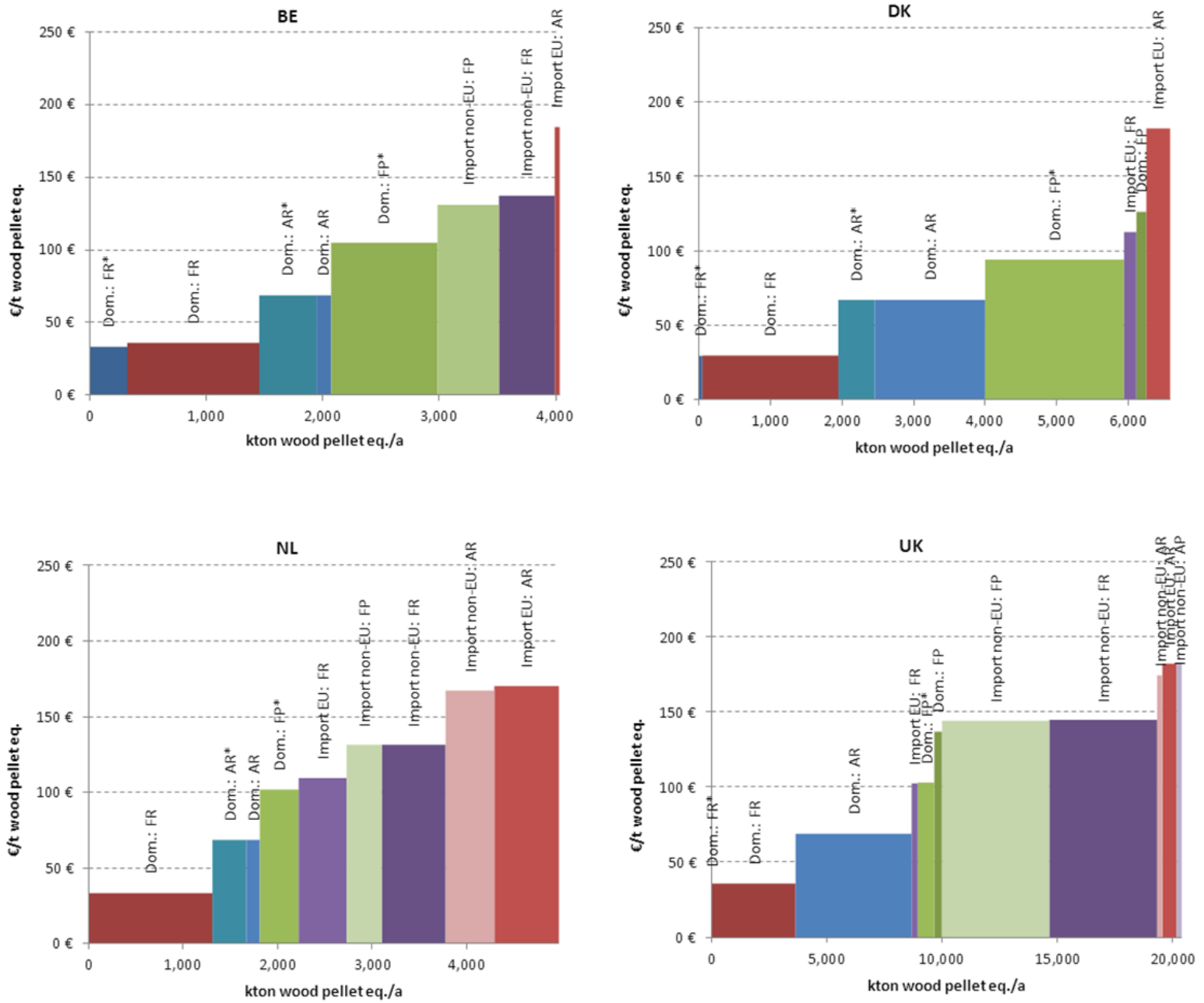

Figure 10. Supply curves across NW Europe under a New Policies Scenario (Lamers et al. 2014a).

Note: $Y$-axis is in Euro per metric tonne of wood pellet equivalent $\left(W P_{e}\right), 100 € /$ tonne $W P_{e}$ reflect US\$113 per ton. The biomass fractions are differentiated by origin (Dom.: domestic, Import-EU: EU imports, Import non-EU: extra-EU imports) and feedstock (FR: forest residues, AR: agriculture residues, FP: pulpwood, AP: energy crops).

\footnotetext{
${ }^{1}$ Assumed energy content for pellets of $16 \mathrm{GJ} / \mathrm{ton}$.

${ }^{2}$ Price for an EU buyer including Cost, Insurance, and Freight (CIF) at the harbors of Antwerp, Rotterdam, or Amsterdam (ARA).
} 
The limiting factor to increase EU import volumes is the production capacity in export regions, not EU demand. All eligible wood and herbaceous pellet volumes were imported across the model runs. The remaining demand was fulfilled from within Europe.

Model runs under stricter EU sustainability requirements for woody biomass pushed herbaceous residue pellets sooner into the supply curves. This increase may however result in technical complications at the power plants (slacking, fouling, etc.). Also, an increased mobilization of these residues will require additional investments in the upstream parts of the supply chain, i.e., collection and conversion. On average, the requirement for sustainability criteria in the EU increased supply costs from US\$136 per ton CIF/ARA (120€/tonne WP ) to US\$169-198 per ton CIF/ARA (150-175€/tonne WP W $_{\text {). }}$

\subsection{Demand across the main EU net importing markets by 2022, 2030, and 2040}

EU demand and biomass supply projections are based on data from the GREEN-X ${ }^{3}$ model. It has been applied in several multi-year European Commission research projects to analyze EU RES targets and related policy schemes in the past. GREEN-X performs detailed quantitative assessments of the future RES deployment on MS, sector, and technology level. The core strengths of the model are the detailed RES, technologies, and specific energy policy trajectories allowing cost-benefit assessments of different policy options. The model is constantly updated with respect to new policy and industry developments. The baseline demand by 2022, 2030, and 2040 across NW Europe (i.e., BE, DK, NL, and UK) reflects to a New Policies Scenario based on models runs in 2013 (Figure 11). Policy updates from 2014 are currently undertaken at the Technical University of Vienna. The baseline data should therefore be seen as preliminary until updates can be incorporated in this project.

The feedstock specific demand (Figure 11) was derived via sector demand assumptions, applied in the estimate for Figure 6 in Section 2.2. This reflects a projection of current practices and industry estimates. The residential heating and industrial heat and power sector rely predominantly on woody biomass, log-/pulpwood in particular. A small fraction is made up of herbaceous material, co-fired, e.g., in Denmark. Furthermore, we assume advanced biofuel production to be based exclusively on herbaceous residues by 2022 , and increasing shares of pulpwood towards 2030 and 2040 for application in thermochemical conversion pathways or as a means to blend herbaceous feedstock in biochemical conversion pathways to achieve quality specifications.

The demand for either herbaceous or woody biomass imports will depend on domestic biomass resource volumes and mobilization costs. Total demand per feedstock is thus first compared to the local supply base for herbaceous (Figure 12) and woody biomass (Figure 13).

\footnotetext{
${ }^{3}$ More information about GREEN-X under: http://www.green-X.at/ [November 26, 2014].
} 


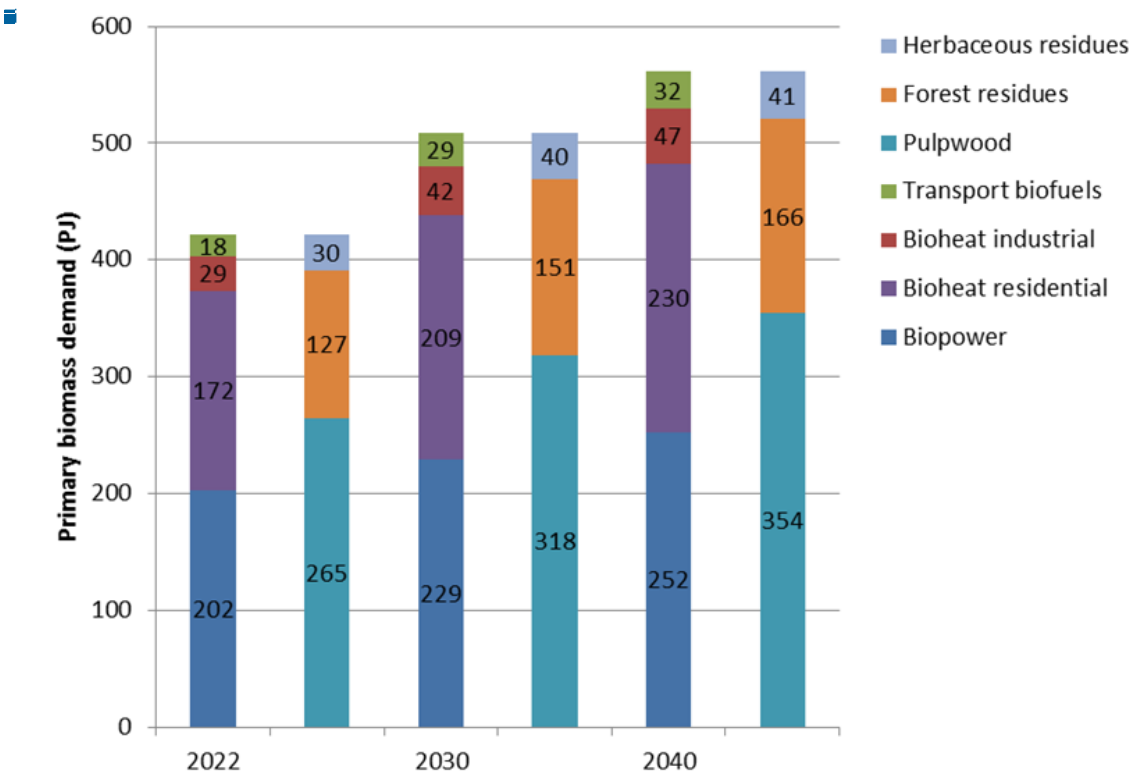

Figure 11. Primary solid biomass demand by sector and feedstock for BE, DK, NL, and the UK (Data: Green-X).

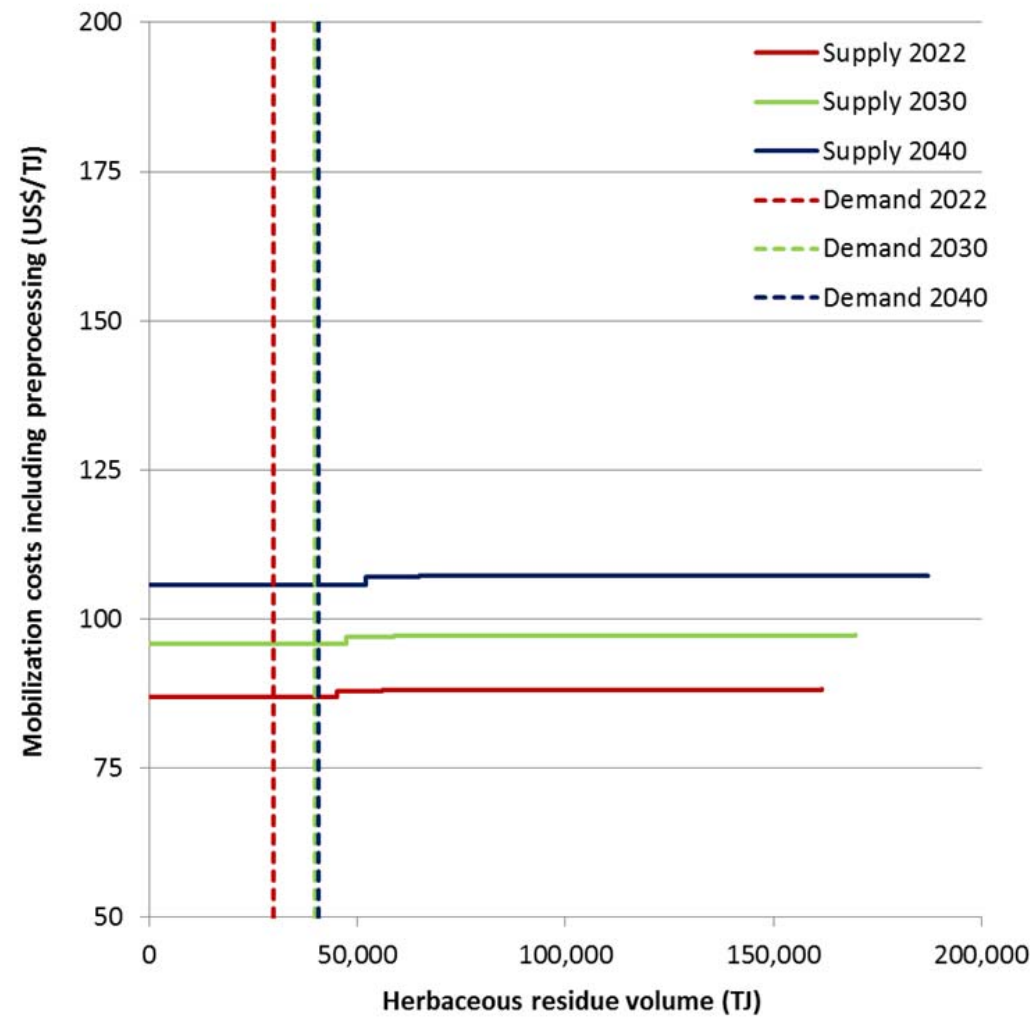

Figure 12. Herbaceous residue supply-costs for BE, DK, NL, UK combined in relation to their demand across 2022, 2030 , and 2040 (Data: Green-X). 
-

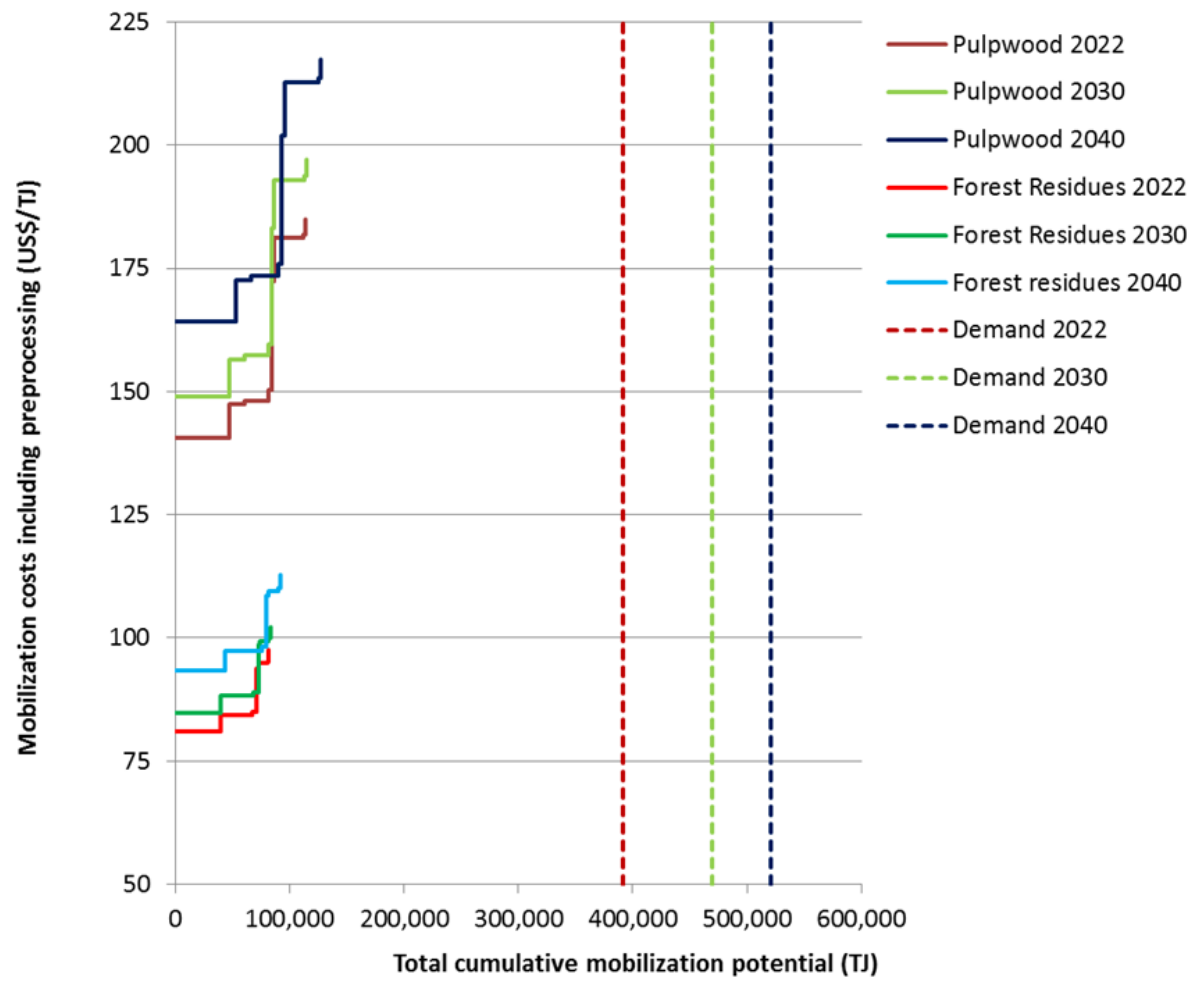

Figure 13. Woody biomass supply costs for BE, DK, NL, and UK combined in relation to their demand by 2022, 2030, and 2040 (Data: Green-X).

The demand for herbaceous biomass across NW Europe for the production of cellulosic biofuels and a $5 \%$ co-firing with woody biomass in industrial-scale heat and power production remains well within the domestic, low-cost supply ranges until 2040 (Figure 12). The domestic supply of woody biomass, however, falls short of the total demand by $197 \mathrm{PJ}$ (12 Mtons) in 2022, $271 \mathrm{PJ}$ (17 Mtons) in 2030, and 302 PJ (19 Mtons) in 2040 over the region (Figure 13).

Assuming that herbaceous residues can be used across any sector at any rate, the local supply will be able to match demand in 2022, and fall short by only 22 PJ (1.35 Mtons) and 24 PJ (1.5 Mtons) in 2030 and 2040, respectively (Figure 16, Appendix). Given current combustion technologies and emission requirements, this scenario is however rather unlikely.

The woody feedstock supply gap (i.e., import dependency) will mostly affect the industrial heat and power sector, and the part of the residential heat sector reliant on wood pellets. The fuelwood demand in the residential sector is typically fulfilled via private forests and regional mobilization of logwood (i.e., pulpwood within this analysis).

Wood pellet imports (based on either pulpwood or forest residues) are competitive to domestic supply, as long as they remain under the domestic supply curve. Assuming that residential fuelwood heating demand would be satisfied domestically, and that all forest residues (low cost woody biomass supply fraction) would be used prior to imports, the additional demand for woody feedstock in the form of pellets reaches 228 PJ (14 Mtons) in 2022, 304 PJ (19 Mtons) in 
2030, and 339 PJ (21 Mtons) in 2040. Imports of this size would compete with the domestic pulpwood pellets up to CIF/ARA costs of:

- 2022: US\$150 per ton,

- 2030: US\$160 per ton,

- 2040: US\$175 per ton.

Or forest residue based pellets up to CIF/ARA costs of:

- 2022: US\$85 per ton,

- 2030: US\$89 per ton,

- 2040: US\$98 per ton.

To assure that traded wood pellets adhere to minimum specifications including density, moisture levels, ash content, and heating value, they can be certified via different quality certification schemes; the most common of which are DINplus, ENplus, CANplus and the Pellet Fuel Institute Standards Program (see Appendix and Wiberg 2014 for a detailed comparison). 


\section{References}

Beringer, T. I. M., W. Lucht and S. Schaphoff (2011). "Bioenergy production potential of global biomass plantations under environmental and agricultural constraints." GCB Bioenergy 3(4): 299-312.

Chum, H., A. Faaij, J. Moreira, G. Berndes, P. Dhamija, H. Dong, B. Gabrielle, A. Goss Eng , W. Lucht, M. Mapako, O. Masera Cerutti, T. Mclntyre, T. Minowa and K. Pingoud (2011). Bioenergy. IPCC Special Report on Renewable Energy Sources and Climate Change Mitigation. O. Edenhofer, R. Pichs-Madruga, Y. Sokona et al. Cambridge, UK and New York, USA, Cambridge University Press.

Clarke, L., K. Jiang, K. Akimoto, M. Babiker, G. Blanford, K. Fisher-Vanden, J. C. Hourcade, V. Krey, E. Kriegler, A. Löschel, D. McCollum, S. Paltsev, S. Rose, P. R. Shukla, M. Tavoni, B. v. d. Zwaan and D. P. v. Vuuren (2014). Assessing Transformation Pathways. Climate Change 2014, Mitigation of Climate Change. Contribution of Working Group III to the Fifth Assessment Report of the Intergovernmental Panel on Climate Change. O. Edenhofer, R. Pichs-Madruga, Y. Sokona et al. Cambridge, United Kingdom and New York, NY, USA, Cambridge University Press.

DOE (2011). U.S. Billion-Ton Update: Biomass Supply for a Bioenergy and Bioproducts Industry. R. D. Perlack and B. J. Stokes. Oak Ridge National Laboratory, Oak Ridge, TN, U.S. Department of Energy: 227.

Goh, C. S., M. Junginger, M. Cocchi, D. Marchal, D. Thrän, C. Hennig, J. Heinimö, L. Nikolaisen, P.-P. Schouwenberg, D. Bradley, R. Hess, J. Jacobson, L. Ovard and M. Deutmeyer (2013). "Wood pellet market and trade: a global perspective." Biofuels, Bioproducts and Biorefining 7(1): 24-42.

Hess, J. R., K. L. Kenney, L. P. Ovard, E. M. Searcy and C. T. Wright (2009). Commodity-Scale Production of an infrastructure-compatible bulk solid from herbaceous lignocellulosic biomass. Uniform-format Bioenergy feedstock supply system design report series, Idaho National Laboratory, USA.

Hoefnagels, R., M. Junginger, C. Panzer, G. Resch and A. Held (2011). Long Term Potentials and Costs of RES - Part I: Potentials, Diffusion and Technological Learning. RE-Shaping (D10), Intelligent Energy - Europe. Utrecht, the Netherlands, Vienna, Austria, Universiteit Utrecht, TU Vienna. http://igitur-archive.library.uu.nl/chem/2012-0320-200511/UUindex.html Accessed 10.09.2013.

Hoefnagels, R., G. Resch, M. Junginger and A. Faaij (2014a). "International and domestic uses of solid biofuels under different renewable energy support scenarios in the European Union." Applied Energy 131(0): 139-157.

Hoefnagels, R., E. Searcy, K. Cafferty, T. Cornelissen, M. Junginger, J. Jacobson and A. Faaij (2014b). "Lignocellulosic feedstock supply systems with intermodal and overseas transportation." Biofuels, Bioproducts and Biorefining early view.

IEA (2014). World Energy Outlook. Paris, International Energy Agency.

Kranzl, L., V. Daioglou, A. Faaij, M. Junginger, K. Keramidas, J. Matzenberger and E. Tromborg (2014). Medium and long-term perspectives of international bioenergy trade. International Bioenergy Trade: History, status \& outlook on securing sustainable bioenergy supply, demand and markets. M. Junginger, C. S. Goh and A. Faaij. Berlin, Springer: 173-189.

Lamers, P., C. Hamelinck, M. Junginger and A. Faaij (2011). "International bioenergy trade - a review of past developments in the liquid biofuels market." Renewable and Sustainable Energy Reviews 15(6): 2655-2676. 
Lamers, P., R. Hoefnagels, M. Junginger, C. Hamelinck and A. Faaij (2014a). "Global solid biomass trade for energy by 2020: an assessment of potential import streams and supply costs to North-West Europe under different sustainability constraints." GCB Bioenergy DOI: 10.1111/gcbb.12162.

Lamers, P., M. Junginger, C. Hamelinck and A. Faaij (2012). "Developments in international solid biofuel trade - an analysis of volumes, policies, and market factors." Renewable \& Sustainable Energy Reviews 16(5): 3176-3199.

Lamers, P., D. Marchal, J. Heinimö and F. Steierer (2014b). Woody biomass trade for energy. International Bioenergy Trade: History, status \& outlook on securing sustainable bioenergy supply, demand and markets. M. Junginger, C. S. Goh and A. Faaij. Berlin, Springer: 4164.

Lamers, P., F. Rosillo-Calle, L. Pelkmans and C. Hamelinck (2014c). Developments in international liquid biofuel trade. International Bioenergy Trade: History, status \& outlook on securing sustainable bioenergy supply, demand and markets. M. Junginger, C. S. Goh and A. Faaij. Berlin, Springer: 17-40.

Rose, S. K., E. Kriegler, R. Bibas, K. Calvin, D. Popp, D. V. Vuuren and J. Weyant (2014). "Bioenergy in energy transformation and climate management. Climatic Change." Climatic Change in press.

Schueler, V., U. Weddige, T. Beringer, L. Gamba and P. Lamers (2013). "Global biomass potentials under sustainability restrictions defined by the European Renewable Energy Directive 2009/28/EC." GCB Bioenergy 5(6): 652-663.

van Vuuren, D., J. van Vliet and E. Stehfest (2009). "Future bio-energy potential under various natural constraints." Energy Policy 37(11): 4220-4220.

Wiberg, C. (2014). Wood Pellet Certification Schemes. Biomass Magazine. http://biomassmagazine.com/articles/10920/wood-pellet-quality-schemes 


\section{Appendix}

\subsection{Bioenergy deployment levels and dynamics with land transformation in long-term climate change mitigation projections $(2050,2100)$}

Bringing atmospheric concentration levels to $550 \mathrm{ppm} \mathrm{CO}_{2 \mathrm{eq}}$ or below by 2100 will require largescale changes to global and national energy systems, and potentially to the use of land (Clarke et al. 2014). Land-use and transformation pathways are directly linked to bioenergy (see Appendix for details).

A review by Chum et al. 2011 of 137 scenarios up to 2050 projected a deployment of 100 to 300 $\mathrm{EJ}$ of biomass for energy globally in 2050 , based on an estimated technical potential for bioenergy between 300 and 500 EJ/year in 2020 and 2050, respectively (Figure 14). A recent comparison in Rose et al. 2014 found that simulated bioenergy structures vary substantially across models, with differences in feedstock assumptions, sustainability constraints, and conversion technologies. At the same time, the scenarios project increasing deployment of, and dependence on, bioenergy with tighter climate change goals, both in a given year as well as earlier in time (Clarke et al. 2014). Shares of total primary energy increase under climate policies due to both increased deployment of bioenergy and higher energy efficiency. Bioenergy's share of total regional electricity and liquid fuels is projected to be up to $35 \%$ and $75 \%$, respectively, by 2050 (Rose et al. 2014). However, there is no single vision about where biomass is cost effectively deployed within the energy system (electricity, liquid fuels, hydrogen, and/or heat), due in large part to uncertainties about relative technology options and costs over time (Clarke et al. 2014).

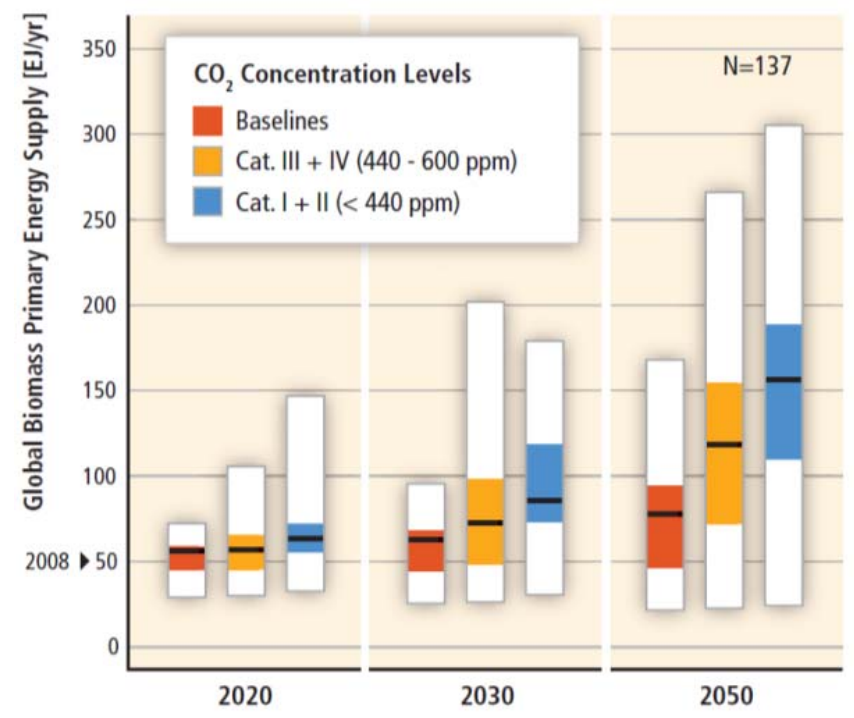

Figure 14. The global primary energy supply from biomass in long-term scenarios (Chum et al. 2011).

A key technology challenge and uncertainty for the expected role of bioenergy in mitigation scenarios is the availability and use of Carbon Capture and Storage (CCS) technologies, and thus bioenergy CCS (BECCS). BECCS could be valuable for reaching lower concentration 
tevets, partly by enabling concentration overshoot. The avallability of BEees is therefore likety to have significant feedback implications for land-use. In scenarios that do include BECCS, it is deployed in greater quantities and earlier in time the more stringent the goal, potentially representing $100 \%$ of bioenergy in 2050 (Figure 15).
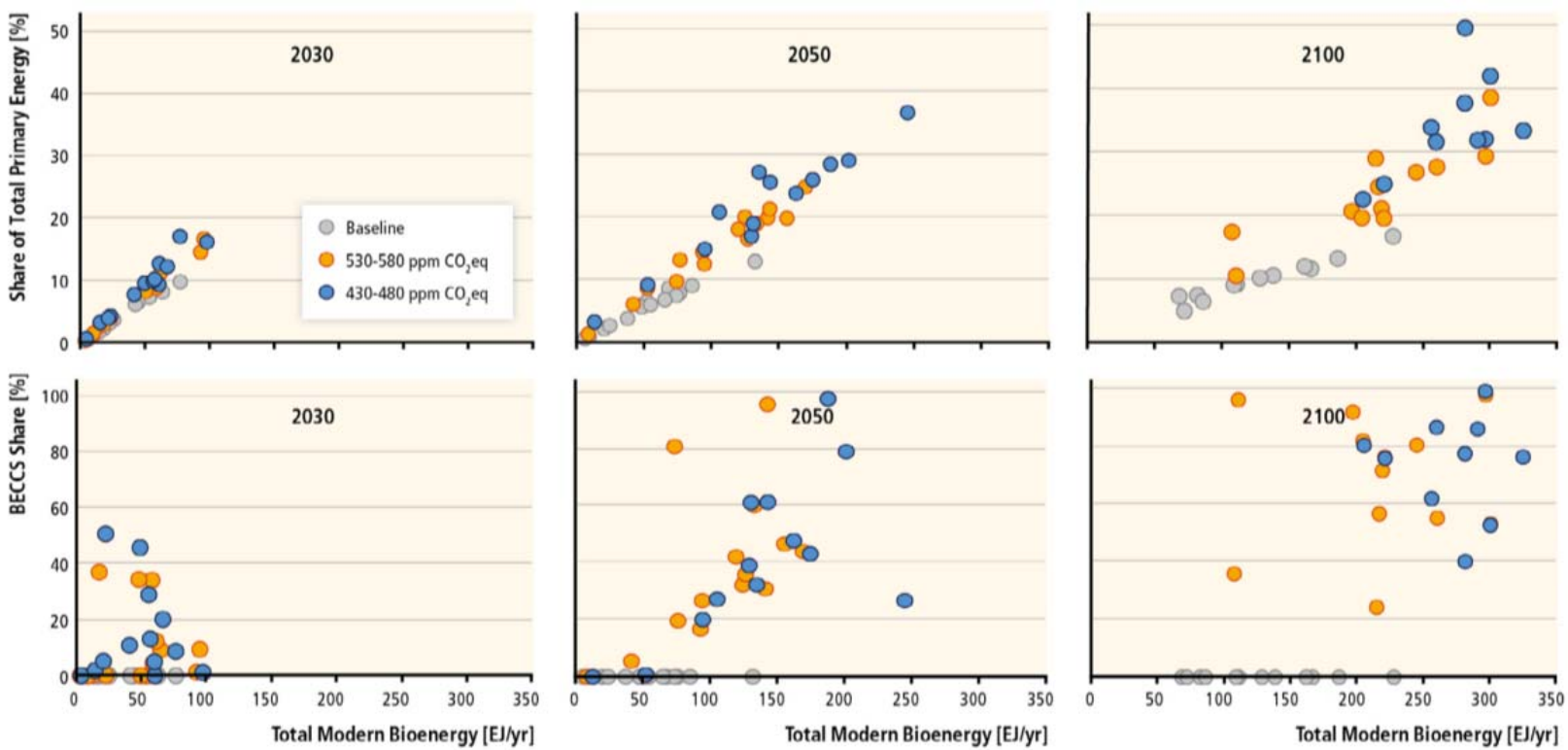

Figure 15. Annual global modern biomass primary energy supply and bioenergy share of total primary energy supply (top panels) and Bioenergy Carbon Capture and Storage (BECCS) share of modern bioenergy (bottom panels) in baseline, $550 \mathrm{ppm}$ and $450 \mathrm{ppm} \mathrm{CO} \mathrm{CO}_{2 \mathrm{q}}$ scenarios in 2030, 2050, and 2100 (Sources: Clarke et al. 2014, Rose et al. 2014).

\section{Excerpt from Clarke et al. 2014:}

The scenarios suggest a substantial cost-effective, and possibly essential, role for land in transformation pathways, with baseline land-use emissions and sequestration an important uncertainty. The key forces associated with mitigation are (1) the demand for bioenergy, (2) the demand to store carbon in land by reducing deforestation, encouraging afforestation, and altering soil management practices, and (3) reductions in non- $\mathrm{CO}_{2} \mathrm{GHG}$ emissions by changing management practices. Other forces include for instance demand for food and forest products, urbanization, and conservation.

A common, but not universal, characteristic of mitigation scenarios is an expansion of energy cropland to support the production of modern bioenergy. There is also a clear tradeoff in the scenarios between energy cropland cover and other cover types. Most scenarios project reduced non-energy cropland expansion, relative to baseline expansion, with some projections losing cropland relative to today. On the other hand, there are projected pasture changes of every kind. Forest changes depend on the incentives and constraints considered in each scenario. Some of the variations in projected land cover change are attributable to specific assumptions, such as fixed pasture acreage, prioritized food provision, land availability constraints for energy crops, and the inclusion or exclusion of afforestation options. Others are more subtle outcomes of combinations of modelling assumption and structure, such as demands for food and energy, land productivity and heterogeneity, yield potential, land production options, and land conversion costs. 
Models universally project that the majority of biomass supply for bioenergy and bioenergy consumption will occur in developing and transitional economies. Rose et al. 2014 found that $50-90 \%$ of global bioenergy primary energy is projected to come from non-OECD countries in 2050, with the share increasing beyond 2050. Developing and transitional regions are also projected to be the home of the majority of agricultural and forestry mitigation. Finally, a number of integrated models have explicitly modelled land-use with full emissions accounting, including indirect land cover change and agricultural intensification. These models have suggested that it could be cost-effective to tradeoff lower land carbon stocks from land cover change and increase $\mathrm{N}_{2} \mathrm{O}$ emissions from agricultural intensification for the long-run climate change management benefits of bioenergy (Rose et al. 2014).

Coordination between land mitigation policies, regions, and activities over time will affect forestry, agricultural, and bioenergy mitigation costs and net GHG mitigation effectiveness. When land options and bioenergy are included in mitigation scenarios, it is typically under the assumption of a highly idealized implementation, with immediate, global, and comprehensive availability of land-related mitigation options. In these cases, models are assuming a global terrestrial carbon stock incentive or global forest protection policy, global incentives for bioenergy feedstocks, and global agriculture mitigation policies. They also assume no uncertainty, risk, or transactions costs.

\subsection{Background and calculation data}

Table 4. Global primary biomass for energy demand for selected countries and regions in EJ (Data: IEA 2014).

\begin{tabular}{|l|r|r|r|r|r|r|r|}
\hline & $\mathbf{1 9 9 0}$ & $\mathbf{2 0 1 2}$ & $\mathbf{2 0 2 0}$ & $\mathbf{2 0 2 5}$ & $\mathbf{2 0 3 0}$ & $\mathbf{2 0 3 5}$ & $\mathbf{2 0 4 0}$ \\
\hline US & 2.6 & 3.7 & 4.7 & 5.5 & 6.4 & 7.5 & 8.3 \\
\hline EU & 2.0 & 5.7 & 7.1 & 7.8 & 8.4 & 9.0 & 9.4 \\
\hline Japan & 0.2 & 0.4 & 0.5 & 0.6 & 0.7 & 0.7 & 0.8 \\
\hline Russia & 0.5 & 0.3 & 0.4 & 0.5 & 0.6 & 0.8 & 1.0 \\
\hline China & 8.4 & 9.0 & 9.6 & 10.0 & 10.4 & 11.0 & 11.4 \\
\hline India & 5.6 & 7.7 & 8.5 & 8.8 & 9.1 & 9.4 & 9.6 \\
\hline Brazil & 2.0 & 3.3 & 4.0 & 4.5 & 5.0 & 5.3 & 5.5 \\
\hline SE Asia & 19.5 & 24.3 & 26.1 & 27.1 & 28.2 & 29.3 & 30.3 \\
\hline
\end{tabular}


Table 5. Primary biomass to feedstock specific demand translation.

\begin{tabular}{|c|c|c|c|}
\hline \multirow[t]{2}{*}{ US } & \multicolumn{3}{|c|}{ Feedstock demand shares } \\
\hline & $\begin{array}{l}2022 \\
P W\end{array}$ & & \\
\hline Power generation & $65 \%$ & $30 \%$ & HR \\
\hline Industry & $65 \%$ & $30 \%$ & $5 \%$ \\
\hline Transport & $0 \%$ & $0 \%$ & $100 \%$ \\
\hline Buildings & $67 \%$ & $33 \%$ & $0 \%$ \\
\hline
\end{tabular}

2030
\begin{tabular}{|r|r|r|}
\hline PW & FR & HR \\
\hline $65 \%$ & $30 \%$ & $5 \%$ \\
\hline $65 \%$ & $30 \%$ & $5 \%$ \\
\hline $10 \%$ & $0 \%$ & $90 \%$ \\
\hline $67 \%$ & $33 \%$ & $0 \%$ \\
\hline
\end{tabular}

2040
\begin{tabular}{|r|r|r|}
\hline PW & FR & HR \\
\hline $65 \%$ & $30 \%$ & $5 \%$ \\
\hline $65 \%$ & $30 \%$ & $5 \%$ \\
\hline $20 \%$ & $0 \%$ & $80 \%$ \\
\hline $67 \%$ & $33 \%$ & $0 \%$ \\
\hline
\end{tabular}

\begin{tabular}{|c|c|c|c|}
\hline \multirow[t]{2}{*}{ EU28 } & \multicolumn{3}{|c|}{$\begin{array}{l}\text { Feedstock demand shares } \\
2022\end{array}$} \\
\hline & PW & FR & $\mathrm{HR}$ \\
\hline Powergeneration & $65 \%$ & $30 \%$ & $5 \%$ \\
\hline Industry & $65 \%$ & $30 \%$ & $5 \%$ \\
\hline Transport & $0 \%$ & $0 \%$ & $100 \%$ \\
\hline Buildings & $67 \%$ & $33 \%$ & $0 \%$ \\
\hline
\end{tabular}
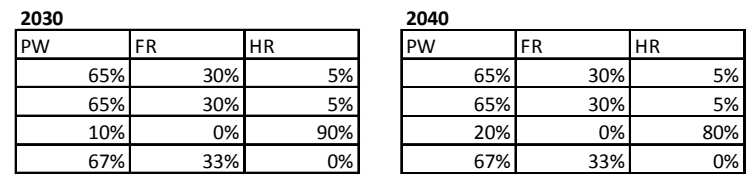

\begin{tabular}{|c|c|c|c|}
\hline \multirow[t]{2}{*}{ Japan } & \multicolumn{3}{|c|}{$\begin{array}{l}\text { Feedstock demand shares } \\
2022\end{array}$} \\
\hline & PW & FR & $\mathrm{HR}$ \\
\hline Power generation & $67 \%$ & $33 \%$ & $0 \%$ \\
\hline Industry & $67 \%$ & $33 \%$ & $0 \%$ \\
\hline Transport & $0 \%$ & $0 \%$ & $100 \%$ \\
\hline Buildings & $67 \%$ & $33 \%$ & $0 \%$ \\
\hline
\end{tabular}
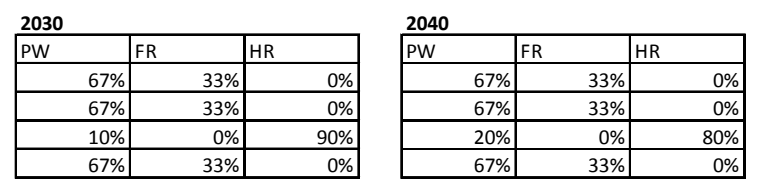

\begin{tabular}{|c|c|c|c|}
\hline \multirow[t]{2}{*}{ Russia } & \multicolumn{3}{|c|}{$\begin{array}{l}\text { Feedstock demand shares } \\
2022\end{array}$} \\
\hline & PW & FR & HR \\
\hline Powergeneration & $67 \%$ & $33 \%$ & $0 \%$ \\
\hline Industry & $67 \%$ & $33 \%$ & $0 \%$ \\
\hline Transport & $0 \%$ & $0 \%$ & $100 \%$ \\
\hline Buildings & $67 \%$ & $33 \%$ & $0 \%$ \\
\hline
\end{tabular}

2030
\begin{tabular}{|r|r|r|}
\hline PW & FR & HR \\
\hline $67 \%$ & $33 \%$ & $0 \%$ \\
\hline $67 \%$ & $33 \%$ & $0 \%$ \\
\hline $10 \%$ & $0 \%$ & $90 \%$ \\
\hline $67 \%$ & $33 \%$ & $0 \%$ \\
\hline
\end{tabular}

\begin{tabular}{l|r|r|}
\hline PW & FR & HR \\
\hline $67 \%$ & $33 \%$ & $0 \%$ \\
\hline $67 \%$ & $33 \%$ & $0 \%$ \\
\hline $20 \%$ & $0 \%$ & $80 \%$ \\
\hline $67 \%$ & $33 \%$ & $0 \%$ \\
\hline
\end{tabular}

\begin{tabular}{|c|c|c|c|}
\hline \multirow[t]{2}{*}{ China } & \multicolumn{3}{|c|}{$\begin{array}{l}\text { Feedstock demand shares } \\
2022\end{array}$} \\
\hline & PW & FR & HR \\
\hline Powergeneration & $0 \%$ & $33 \%$ & $67 \%$ \\
\hline Industry & $0 \%$ & $33 \%$ & $67 \%$ \\
\hline Transport & $0 \%$ & $0 \%$ & $100 \%$ \\
\hline Buildings & $33 \%$ & $33 \%$ & $33 \%$ \\
\hline
\end{tabular}

2030
\begin{tabular}{|r|r|r|}
\hline PW & FR & HR \\
\hline $0 \%$ & $33 \%$ & $67 \%$ \\
\hline $0 \%$ & $33 \%$ & $67 \%$ \\
\hline $0 \%$ & $0 \%$ & $100 \%$ \\
\hline $33 \%$ & $33 \%$ & $33 \%$ \\
\hline
\end{tabular}

2040
\begin{tabular}{|r|r|r|}
\hline PW & FR & HR \\
\hline $0 \%$ & $33 \%$ & $67 \%$ \\
\hline $0 \%$ & $33 \%$ & $67 \%$ \\
\hline $0 \%$ & $0 \%$ & $100 \%$ \\
\hline $33 \%$ & $33 \%$ & $33 \%$ \\
\hline
\end{tabular}

\begin{tabular}{|c|c|c|c|}
\hline \multirow[t]{2}{*}{ India } & \multicolumn{3}{|c|}{$\begin{array}{l}\text { Feedstock demand shares } \\
2022\end{array}$} \\
\hline & PW & FR & HR \\
\hline Power generation & $0 \%$ & $33 \%$ & $67 \%$ \\
\hline Industry & $0 \%$ & $33 \%$ & $67 \%$ \\
\hline Transport & $0 \%$ & $0 \%$ & $100 \%$ \\
\hline Buildings & $33 \%$ & $33 \%$ & $33 \%$ \\
\hline
\end{tabular}

2030
\begin{tabular}{|r|r|r|}
\hline PW & FR & HR \\
\hline $0 \%$ & $33 \%$ & $67 \%$ \\
\hline $0 \%$ & $33 \%$ & $67 \%$ \\
\hline $0 \%$ & $0 \%$ & $100 \%$ \\
\hline $33 \%$ & $33 \%$ & $33 \%$ \\
\hline
\end{tabular}

2040
\begin{tabular}{|r|r|r|}
\hline PW & FR & HR \\
\hline $0 \%$ & $33 \%$ & $67 \%$ \\
\hline $0 \%$ & $33 \%$ & $67 \%$ \\
\hline $0 \%$ & $0 \%$ & $100 \%$ \\
\hline $33 \%$ & $33 \%$ & $33 \%$ \\
\hline
\end{tabular}

\begin{tabular}{|c|c|c|c|}
\hline \multirow[t]{2}{*}{ Russia } & \multicolumn{3}{|c|}{$\begin{array}{l}\text { Feedstock demand shares } \\
2022\end{array}$} \\
\hline & PW & FR & HR \\
\hline Powergeneration & $0 \%$ & $33 \%$ & $67 \%$ \\
\hline Industry & $0 \%$ & $33 \%$ & $67 \%$ \\
\hline Transport & $0 \%$ & $0 \%$ & $100 \%$ \\
\hline Buildings & $33 \%$ & $33 \%$ & $33 \%$ \\
\hline
\end{tabular}

2030
\begin{tabular}{|r|r|r|}
\hline PW & FR & HR \\
\hline $0 \%$ & $33 \%$ & $67 \%$ \\
\hline $0 \%$ & $33 \%$ & $67 \%$ \\
\hline $0 \%$ & $0 \%$ & $100 \%$ \\
\hline $33 \%$ & $33 \%$ & $33 \%$ \\
\hline
\end{tabular}

2040
\begin{tabular}{|r|r|r|}
\hline PW & FR & HR \\
\hline $0 \%$ & $33 \%$ & $67 \%$ \\
\hline $0 \%$ & $33 \%$ & $67 \%$ \\
\hline $0 \%$ & $0 \%$ & $100 \%$ \\
\hline $33 \%$ & $33 \%$ & $33 \%$ \\
\hline
\end{tabular}




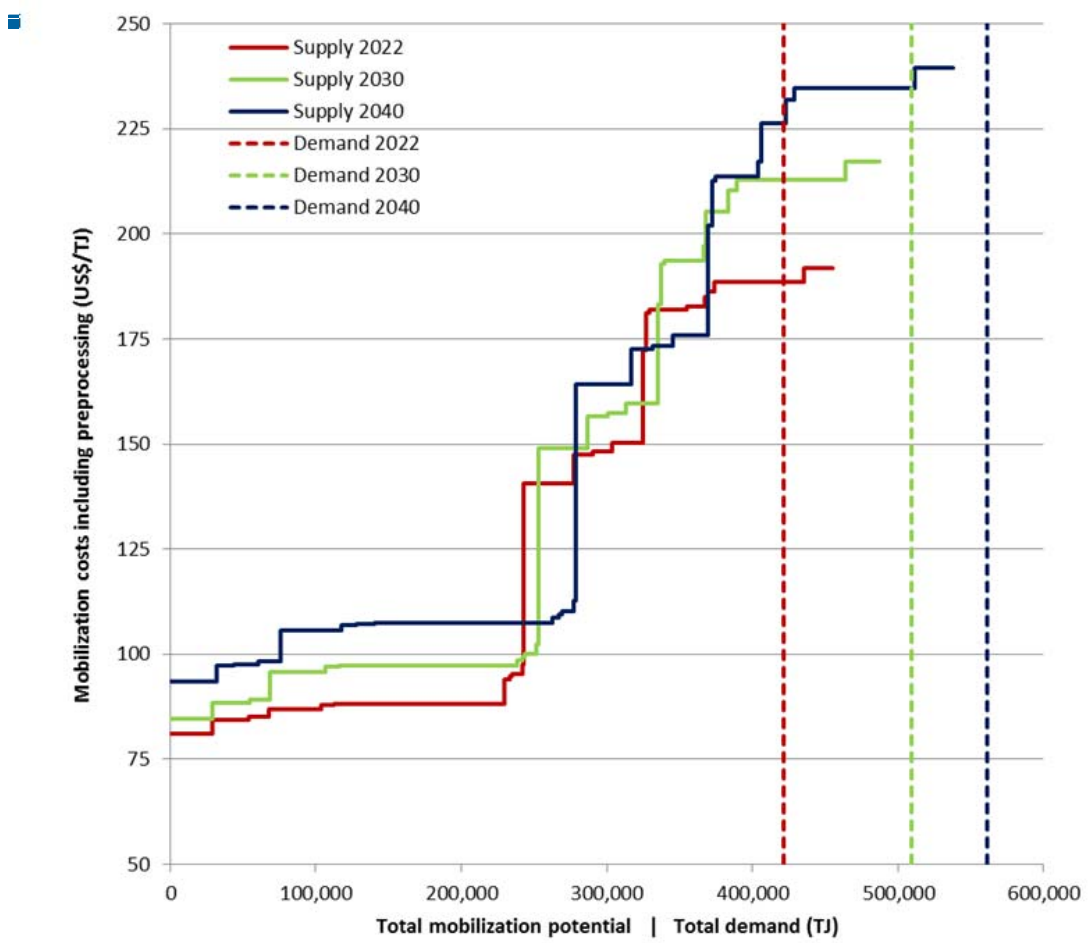

Figure 16. Total solid biomass (woody and herbaceous feedstock) supply and demand across BE, DK, NL, and UK combined (Data: Green-X). 


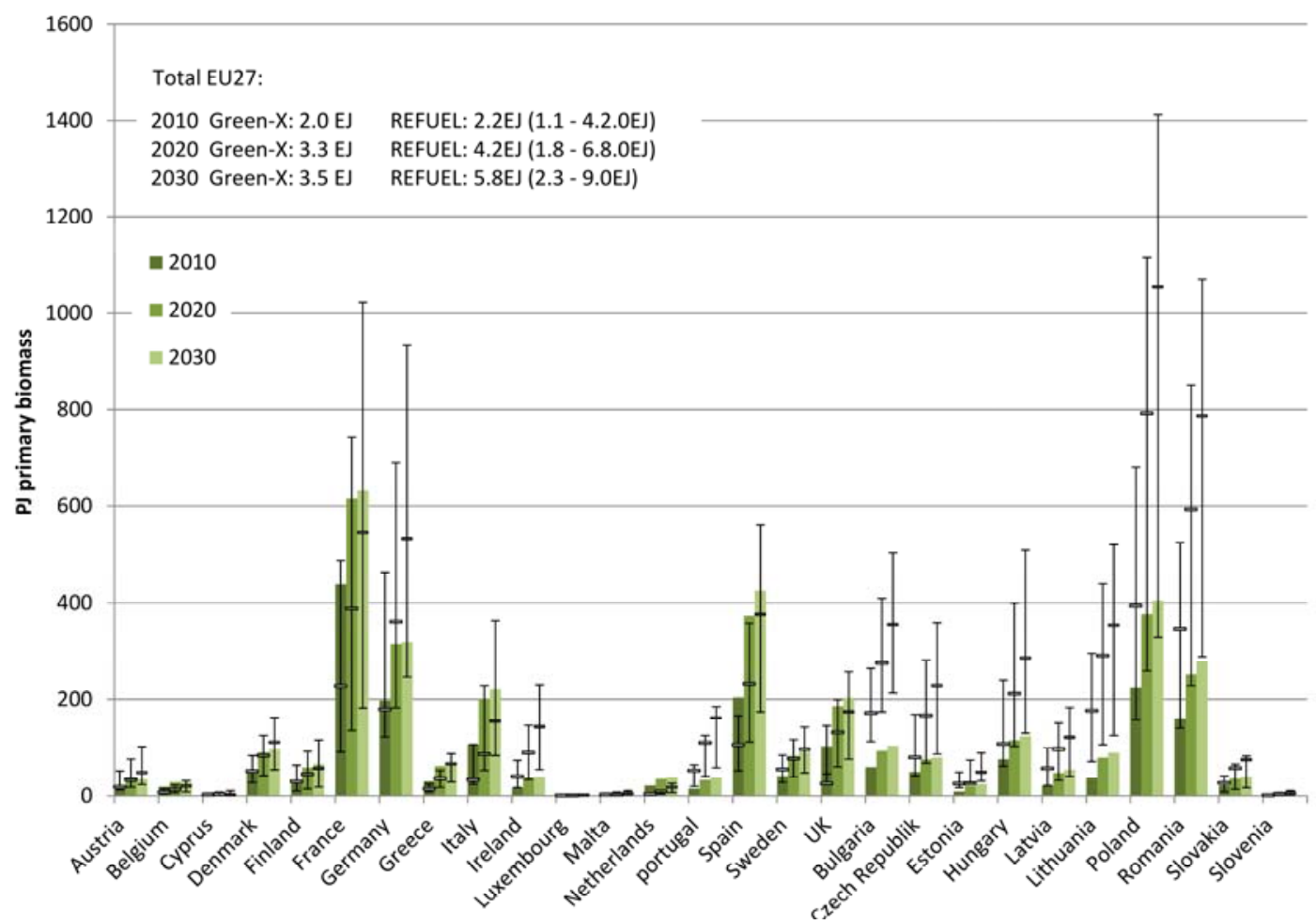

Figure 17. Supply potential of dedicated energy crops in the EU27 for Green-X (columns) and REFUEL (markers) for the same crop type production mix (Hoefnagels et al. 2011).
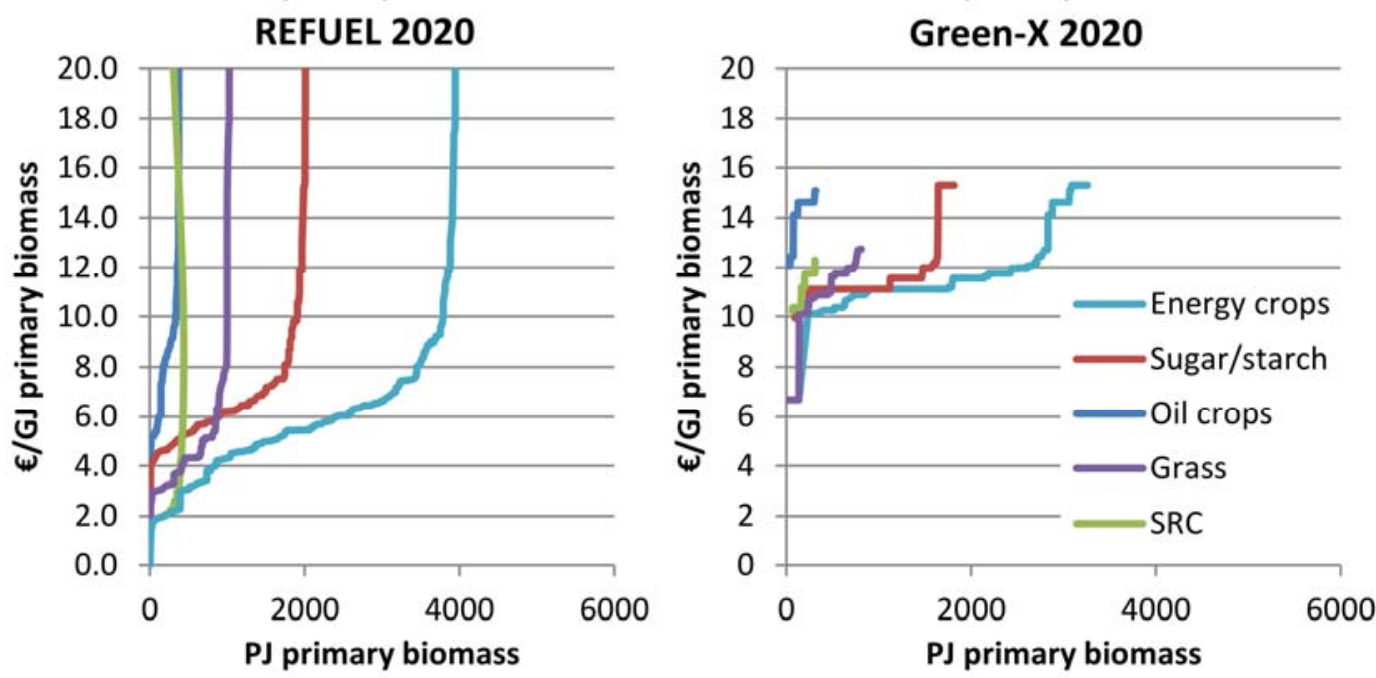

Figure 18. Farm gate cost-supply curves for bioenergy crops in the EU27 in Refuel and Green-X for the same crop type production mix (Hoefnagels et al. 2011). 

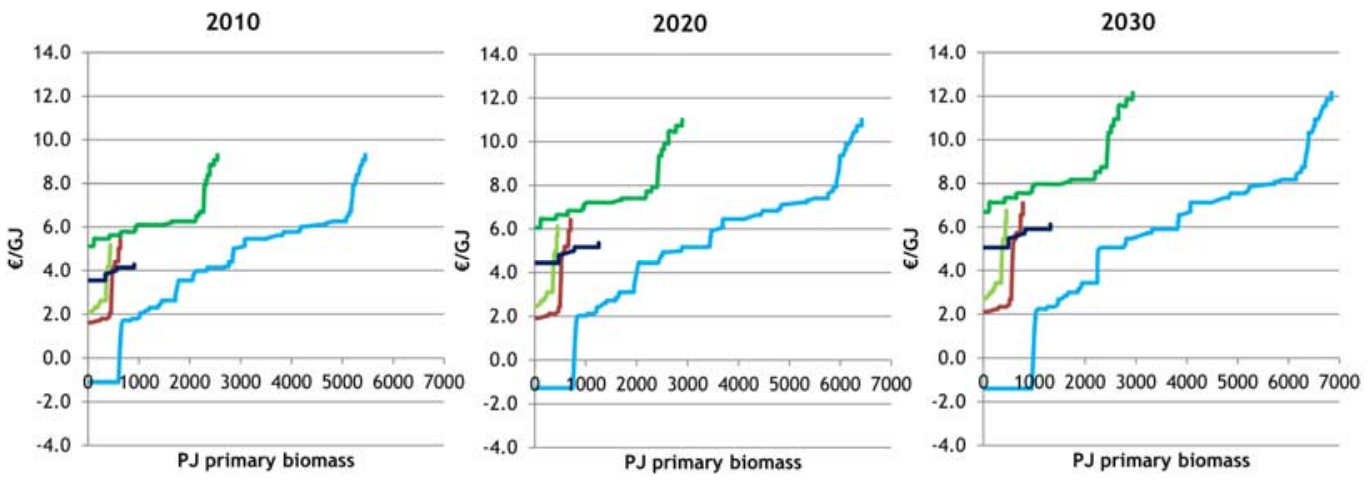

— Forestry products — Forestry residues — Forestry residues (secondary) _ Agricultural residues — Waste — All residues and waste

Figure 19. Cost-supply curves of forestry products (primary and secondary), agricultural residues and waste in Green-X. The waste curve is not visible, as it completely overlaps with the first horizontal line of the overall supply curve.

(Hoefnagels et al. 2011).
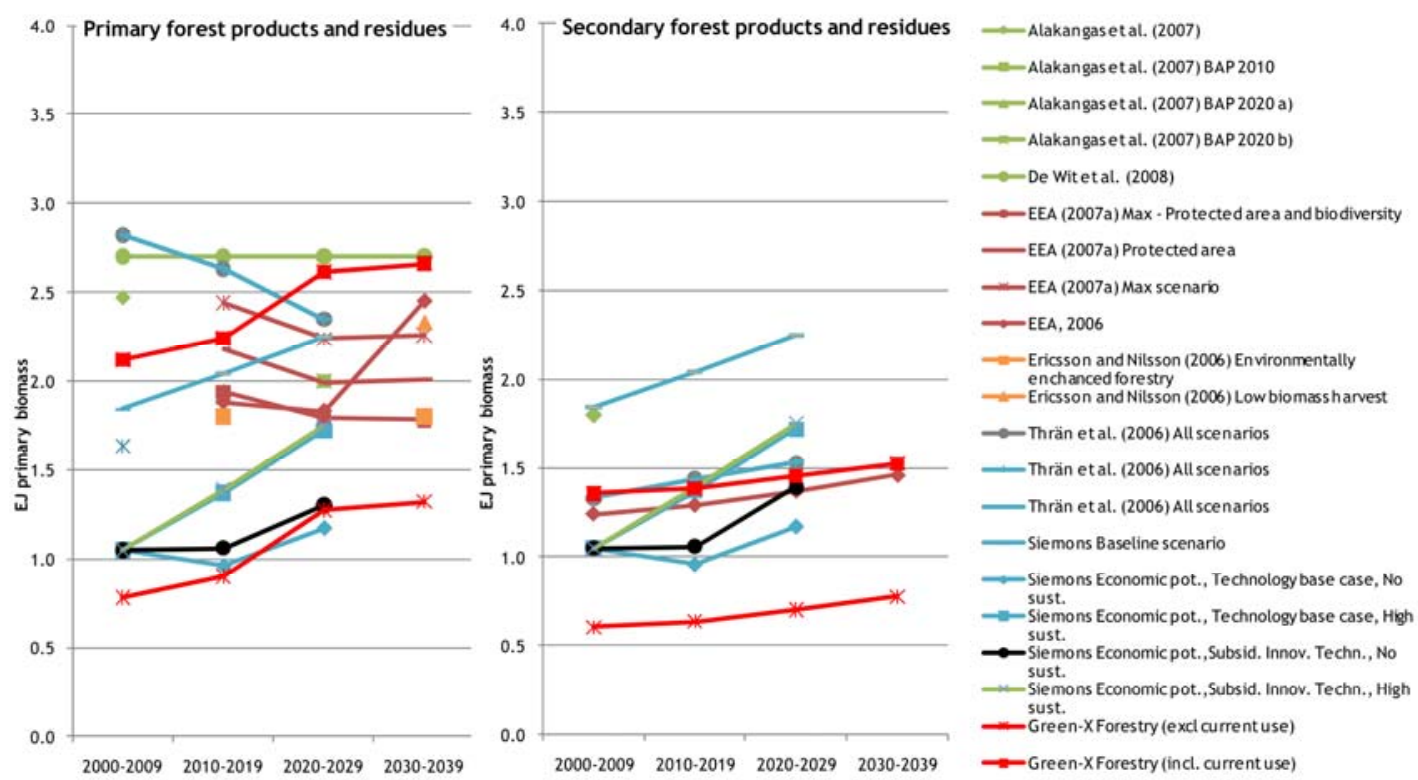

Figure 20. Total forestry potential (calibrated for the EU27) of stemwood and primary forestry residues (left) and secondary forestry residues (right) (Hoefnagels et al. 2011). 


\subsection{Wood Pellet Quality Schemes}

Overview of the similarities and primary differences of the major pellet quality certification schemes: DINplus, ENplus, CANplus and the Pellet Fuel Institute Standards Program.

Excerpt from Wiberg 2014:

All provide a means by which pellet fuel producers can adhere to an established set of quality control and quality assurance measures to assure that the overall pellet production operation is committed to a quality process. In addition, each defines product grades and grade criteria to which the product is tested to verify compliance with the grade, and each provides a label that compliant producers can print on their bags or include with their bulk material shipping documents to signify quality. All of these quality schemes incorporate third-party auditing and testing and all of these schemes are overseen by an accreditation or certification body. [...]

DINplus was the first scheme, established in 2002 by DIN Certco in Germany. It was primarily applied in European residential heating markets. It has lost popularity and market coverage since the 2011 introduction of the ENplus quality scheme, which expanded the scope of certification across the entire supply chain, including trader certification, and tracking for GHG emissions and sustainability. ENplus is based on the EU standard for wood pellets (EN 14961-2) and is anticipated to reference the newly developed ISO wood pellet standards (ISO 17225-2) with the next draft. Due to a robust acceptance within European heating markets, wood pellet producers from North America that are reasonably accessible to export trade routes can find great value in certifying to the ENplus quality scheme. Within North American markets, however, ENplus has been slow to emerge.

In recent years, Canada has also developed a wood pellet quality scheme called CANplus, which is essentially the same as ENplus, in that wood pellet producers first certify to ENplus and then apply to the Wood Pellet Association of Canada for CANplus certification. The primary difference between the two is that the CANplus quality mark uses the red maple leaf, and is intended for Canadian residential heating markets.

While DINplus, ENplus and CANplus are all based on the European Union and ISO standards (references grades criteria for A1, A2, and B based on EN 14961-2 or ISO 17225-2), the PFI Standards Program is the one quality scheme that currently reflects historical North American grade criteria-premium, standard and utility grades. PFI released the first version of its quality scheme in 2008. In 2010, the U.S. EPA made it known that it intended to regulate residential wood combustion appliances and the next year, PFI made substantial modifications to assure that the PFI quality scheme would comply with the EPA's anticipated requirements. The new rule is not yet finalized, but it is expected the U.S. EPA will reference the PFI quality scheme as part of its regulation. 